Atmos. Chem. Phys. Discuss., 10, 11009-11046, 2010 www.atmos-chem-phys-discuss.net/10/11009/2010/ (C) Author(s) 2010. This work is distributed under the Creative Commons Attribution 3.0 License.
Atmospheric

Chemistry and Physics Discussions

This discussion paper is/has been under review for the journal Atmospheric Chemistry and Physics (ACP). Please refer to the corresponding final paper in ACP if available.

\title{
Probabilistic model of shattering effect on in-cloud measurements
}

V. Shcherbakov ${ }^{1,2}$, J.-F. Gayet ${ }^{1}$, G. Febvre ${ }^{1}$, A. J. Heymsfield ${ }^{3}$, and G. Mioche ${ }^{1}$

${ }^{1}$ Laboratoire de Météorologie Physique, UMR/CNRS 6016, Université Blaise Pascal, 24 avenue des Landais, 63177 Aubière Cedex, France

${ }^{2}$ LaMP - Institut Universitaire de Technologie de Montluçon, Avenue A. Briand-BP 2235, 03101 Montluçon Cedex, France

${ }^{3}$ National Center for Atmospheric Research, Boulder, Colorado, USA

Received: 24 February 2010 - Accepted: 19 April 2010 - Published: 26 April 2010

Correspondence to: V. Shcherbakov (shcherbakov@moniut.univ-bpclermont.fr)

Published by Copernicus Publications on behalf of the European Geosciences Union.

\section{ACPD}

$10,11009-11046,2010$

Probabilistic model of shattering effect on in-cloud measurements

V. Shcherbakov et al.

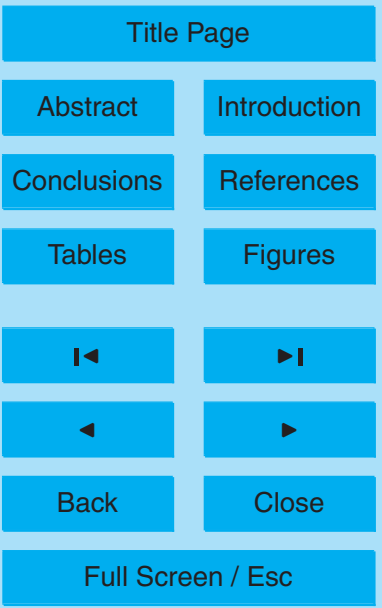

Printer-friendly Version

Interactive Discussion 


\section{Abstract}

A probabilistic model of the ice shattering effects on in-cloud measurements performed with instruments designed with inlets, which have the circular cross-section, is presented. Applications are made for the Polar Nephelometer and PMS FSSP instru-

5 ments. The model provides rough estimates of the effects on microphysical measurements and assigns the key parameters that govern the efficiency of ice shattering. It is shown that experimental data are less affected by the shattering for clouds that have a lower proportion of large particles. The effects on derived integral microphysical parameters are shown to be very sensitive to the effective diameter of the ice fragments.

10 The smaller the fragments from a given cloud particle are, the higher their effects are. Errors on Polar Nephelometer measurements were evaluated. It is shown that the ice particle shattering leads to the overestimation of the extinction coefficient. For example, for a given distribution with the effective diameter of $68 \mu \mathrm{m}$ and with fragment effective diameters of $10 \mu \mathrm{m}$ the extinction is overestimated by $25 \%$. With larger particles having an effective diameter of $89 \mu \mathrm{m}$, the error increases up to $37 \%$. As for the FSSP-300 instrument, under the same conditions the extinction coefficient is overrated by $17 \%$ and the number particle concentration is overestimated by $30 \%$. The discussion of the results points out the main hypothesis which may seriously limit the reliability of the modelling results. Nevertheless, the magnitudes of the errors on extinction and particle concentration are of the same orders of those reported in the literature from experimental assessments.

\section{Introduction}

Airborne in situ instruments have intensively been used on aircraft to measure microphysical characteristics of warm, mixed and ice clouds for several decades. The ob25 served experimental data are widely used for cloud parameterizations for many applications such as cloud process studies, general circulation models, validation of remote

\section{Probabilistic model of shattering effect on in-cloud measurements}

V. Shcherbakov et al.

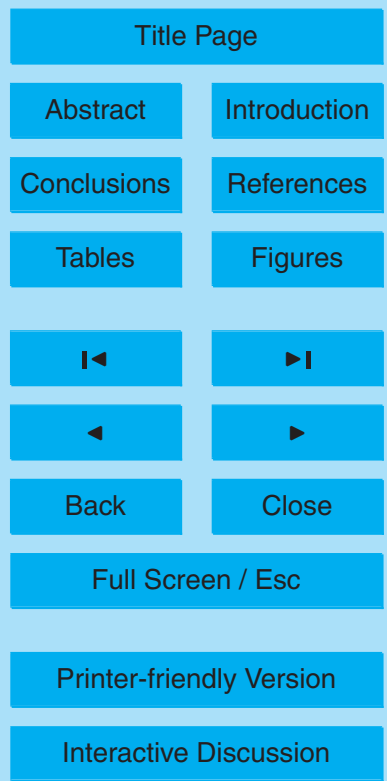


sensing techniques, assessment of cloud radiative forcing and so on.

At the same time, for many years it has been recognized that some aircraft cloud microphysical measurements may be contaminated by hydrometeors shattering or splashing when they collide with the probe inlets (Heymsfield, 2007). Gardiner and 5 Hallett (1985) showed that in the presence of large, irregular ice crystals the FSSP droplet spectra may be artificially enhanced by 2-3 orders of magnitude. Gayet et al. (1996) compared FSSP and 2D-C measurements and concluded that FSSP concentrations are exaggerated in cirrus with large crystals (i.e., maximal particle size up to $700 \mu \mathrm{m}$ ). Field et al. (2003) came to the conclusion that shattering may result in 10 overcounting of ice particles measured by FSSP in the midlatitude cirrus by factor of 2 to 5 . Techniques were proposed by Field et al. $(2003,2006)$ to separate genuine small particles from shattering artefacts using ice particle interarrival times (from either FastFSSP or 2D-C probes), thus making objective corrections possible. Korolev and Isaac (2005) concluded that the fraction of shattered particles may make up more than $10 \%$ 15 of the total number of particles sampled by the OAP-2DP. Heymsfield (2007) showed that there are linear relationships between the ice water content (IWC) in large particles and those detected by the FSSP and the cloud and aerosol spectrometer (CAS). The within-cloud condensation nuclei measurements may be an artifact of the sampling process because of droplet splashing on the edge of the inlet (Hudson and Frisbie, 1991).

20 Baker et al. (2009) pointed out that splashing events on the 2D-S probe are a regular occurrence in the presence of raindrops. Moreover, Jensen et al. (2009) emphasized that the observed difference in 2D-S measurements from DC-8 and WB-57 flight legs during the Tropical Composition, Cloud, and Climate Coupling (TC4) campaign may be an indication of shattering off the leading edge of the WB-57 wing affecting the 2D-S

25 measurement at the wing-hatch location. In the following, we discuss only shattering artifacts, which are directly related to the instrument itself. On the other hand, it is reasonable that not all data of in-cloud measurements should be considered as erroneous. For example, Garrett (2007) concluded that the Cloud-Integrating Nephelometer (CIN) is insensitive to shattering of precipitation-sized particles on its aperture. At the same

\section{Probabilistic model of shattering effect on in-cloud measurements}

V. Shcherbakov et al.

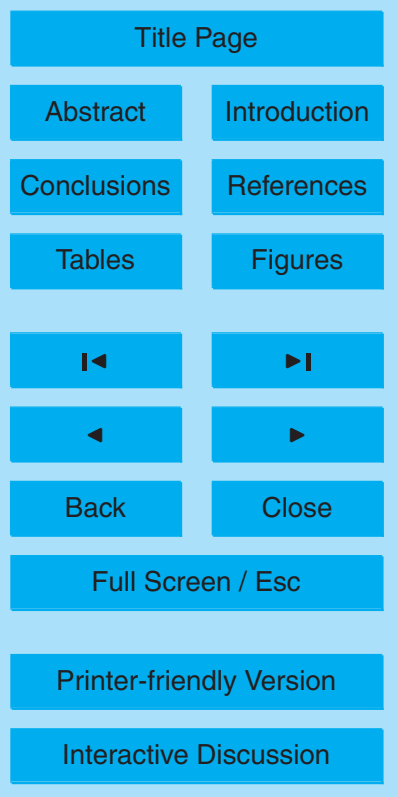

11011 
time, Heymsfield et al. (2007) suggested that measurements from both the cloud integrating nephelometer $(\mathrm{CIN})$ and the FSSP instruments may be similarly contaminated by ice particle shattering.

A large dataset of microphysical and optical characteristics of cirrus clouds (see 5 Gayet et al., 2006 and citations therein) was obtained during the INCA (INterhemispheric differences in Cirrus properties from Anthropogenic emissions) experiment (Ström et al., 2001). The instruments used for the measurements have already been thoroughly described by Gayet et al. (2004). Three independent techniques were used in that study: (1) the PMS (Particle Measuring System) FSSP-300 (Forward Scattering 10 Spectrometer Probe) operated by the DLR (Deutsches Zentrum für Luft- und Raumfahrt), (2) the PMS 2D-C and (3) the Polar Nephelometer (PN) probes, both operated by the LaMP (Laboratoire de Météorologie Physique). The same set of instruments was employed in several campaigns during recent years. Thus, it is of importance to estimate the ice shattering effects in relation to those instruments. This work concerns only the Polar Nephelometer and the FSSP instrument. As for the PMS 2D-C probe, we note in passing that since 2001 the LaMP's operational algorithm rejects frames with three and more isolated images. Consequently, shattering could result in an undercounting of real large particles (see, Korolev and Isaac, 2005).

The shattering of actual ice particles into several smaller ice fragments may occur due to 1) mechanical impact with the probe arms (PN, FSSP, 2D-C) and/or the inlet shroud (PN, FSSP) prior to their entering the sampling volume, and 2) fragmentation due to interaction with turbulence and wind shear generated by the probe housing (see, e.g., Korolev and Isaac, 2005). The shattering efficiency depends on a large set of parameters, namely, the habit, size, and density of cloud particles, probe inlet-shroud design (Korolev and Isaac, 2005), the airspeed and the impact angle with respect to the airflow (Weber et al., 1998). Thus, a number of physical processes have to be considered in an effort to evaluate effects of the shattering on airborne measurements. The exact solution of this problem is extremely arduous, if not to say impossible, task. Thus, the use of simplified models or approximations could be useful tools that are

\section{Probabilistic model of shattering effect on in-cloud measurements}

V. Shcherbakov et al.

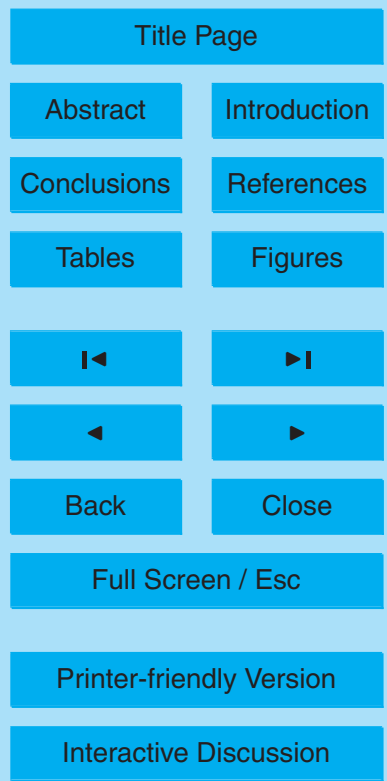


able to provide rough estimates of the shattering effects on in-cloud measurements. Because the Polar Nephelometer and the FSSP probes have inlets with circular crosssection (see sketches on Fig. 1) a common model of the shattering can be proposed for these two instruments. The aim of this paper is to present a probabilistic model of 5 ice shattering effects on Polar Nephelometer and FSSP measurements. This work is a first attempt to obtain rough estimates of measurement errors caused by the shattering or the splashing of cloud particles. The concept and the results may initiate more sophisticated models and may be used for the design of oriented wet wind tunnel experiments.

10 The paper is organized as follows: the probabilistic model is described first, thereafter the results of case study are presented. Finally, the last section is devoted to the discussion and to the practical application.

\section{The model of ice particle shattering}

\subsection{Description of the probabilistic model}

15 When the shattering effect is discussed in the literature, the emphasis is usually on fragments that are measured as cloud particles. In other words, the main attention is given to the additional component that may result in overestimation of derived cloud properties (extinction coefficient for instance) and in overcounting of ice particles concentration measured by the FSSP.

20 Generally, impacting cloud-particles are identified as the source of fragments. At the same time, the question whether the ensemble of the sampled non-shattered particles differs from the ensemble of actual cloud particles is usually neglected. To get an answer on this question, it will suffice to imagine an instrument inlet having a crosssection diameter, for example, of $100 \mu \mathrm{m}$. It is obvious that such an instrument cannot measure particles having a size of $100 \mu \mathrm{m}$ or higher. Therefore, for all in-cloud instruments which are designed with an inlet to drive cloud particles into the sampling

\section{Probabilistic model of shattering effect on in-cloud measurements}

V. Shcherbakov et al.

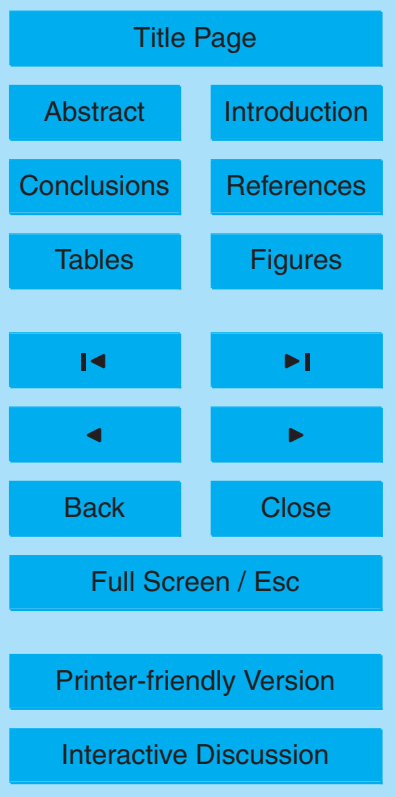

11013 
section, not only ice fragments resulting from the shattered particles may affect the measured data, but the size distribution of the sampled cloud particles may be altered as well. Consequently, we consider the shattering effects on in-cloud measurements that are governed by two processes. The first one is the loss of cloud particles (which 5 are assumed to be shattered) due to collisions with the tip of the probe inlet shroud. Thus, the measured size distribution of the particles, which are not shattered, is not equal to the actual size distribution of cloud particles. Moreover, we consider the loss of cloud particles as the unavoidable source of fragments for an instrument designed with an inlet or a shroud. The second process is a direct consequence of the first one, 10 that is, some fragments of the shattered particles are sampled by the probe as cloud particles.

Hereafter, we will use the term "shattered particles" to mean actual cloud particles that will impact with the probe inlet tube and shatter. The term "fragments" will be used for particles resulting from shattering. A "sampled" or "measured" particle (nonshattered particle and/or fragment) is a particle, which goes through the probe sampling volume and then is recorded.

As it was mentioned above, the use of simplifications or approximations is inevitable in an effort to evaluate effects of the shattering on measurements. At the same time, any approach has to take into account the stochastic nature of the problem. Our simple,

if not to say simplest, model does not consider physical processes associated with the air flow through an instrument. The model is wholly probabilistic, i.e., it is based on the probability that a particle is shattered and on the probability that a fragment is sampled as a cloud particle.

In this study the Polar Nephelometer (Gayet et al., 1997) and the FSSP (Baumgard25 ner et al., 1992) probes will be considered. They both have inlets designed with a circular cross-section (see sketches on Fig. 1). We note in passing that the methodology described in this paper can easily be applied to airborne instruments, which also have circular inlets, for example, the Cloud Particle Imager (CPI, Lawson et al., 2001). Let us consider the idealized Polar Nephelometer (PN) and FSSP inlet-shroud cross-

\section{Probabilistic model of shattering effect on in-cloud measurements}

V. Shcherbakov et al.

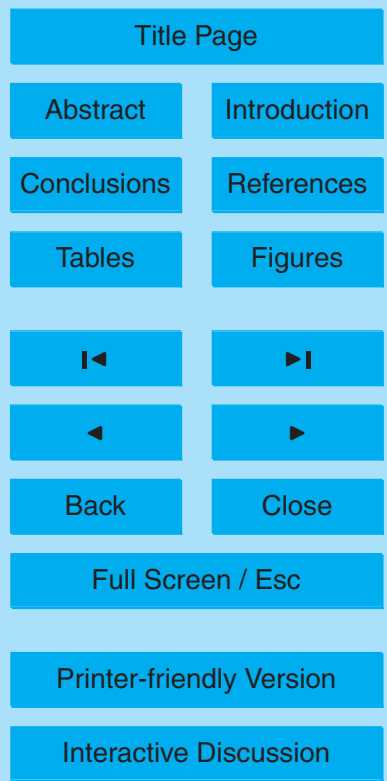


sections shown by the bold circle labelled A (see scheme on Fig. 2). Therefore the particles go in the direction that is perpendicular to the figure plane.

The spatial distributions of cloud particles and of all fragments (which result from of the shattered particles) within the inlet cross-section are assumed to be homoge-

5 neous. Generally, the homogeneous distribution of particles in a sampled cloud is not a simplification.

The spatial distribution of the fragments is likely related to the design of the probe inlet and/or shroud via both the aerodynamic flow inside the probe inlet and/or shroud and the aerodynamic size (and morphology) of the particles (King, 1986). Therefore 10 the spatial distribution of the fragments will depend on the airspeed and the distances (i) between the sampling volume (represented by red lines on Fig. 1) and the inlet inner-edge, and (ii) between the sampling volume and the leading edge of the inlet (see Fig. 1). Specific modelling of fragments trajectories inside of probe inlets is not available to our knowledge. This issue is beyond the scope of this paper and could be 15 the object of forthcoming works. Oriented wet wind tunnel tests could also help in a better understanding of the spatial distribution of the fragment particles along the probe inlet. The spatial distribution of fragments is assumed to be homogeneous in our model for simplicity sake. The PN data are expected to be less sensitive to that simplification because the PN sampling area is large with regard to the inlet cross-section $\left(50 \mathrm{~mm}^{2}\right.$ 20 versus $80 \mathrm{~mm}^{2}$ respectively) and thus most of fragments are sampled (see Fig. 1). The FSSP sampling area is much smaller than the inlet cross-section $\left(0.5 \mathrm{~mm}^{2}\right.$ versus $1300 \mathrm{~mm}^{2}$ respectively). Therefore, if the fragments are inhomogeneously distributed, the ice water content (IWC) carried by the sampled fragments could significantly differ from the IWC of the shattered particles. In the case when most of fragments go prefer25 entially along the inlet axis and are measured by the FSSP, the IWC of fragments will be larger than the IWC of shattered particles. That is, the ratio of the IWC of fragments to the IWC of shattered particles will be greater than one. This IWC ratio will be smaller than one when most of fragments go preferentially near the inlet border and miss the sampling volume. In the following, that ratio is assumed to be equal to one.

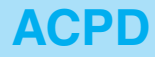

$10,11009-11046,2010$

\section{Probabilistic model of shattering effect on in-cloud measurements}

V. Shcherbakov et al.

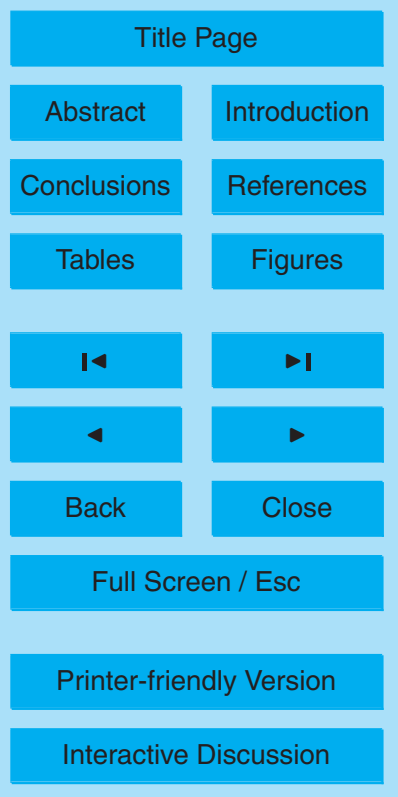


The width of the inlet leading edge schematized by the width of the line A on Fig. 2, is assumed to be a negligibly small quantity. The validity of that assumption depends on the design of the inlet tip. It seems to be appropriate for the Polar Nephelometer, but not for some designs of the FSSP (see Fig. 1). The larger the width of the leading 5 edge (represented by the line A) is, the higher the shattering effect should be.

All particles in a sampled cloud and all fragments are assumed to be spheres. Despite the fact that particle fragments and ice crystals of cirrus or mixed clouds are not spherical, this assumption is used because it provides a radical simplification of all following calculations.

10 Because the spatial distribution of particles is homogeneous, the 2D distribution of centre-of-masses of the cloud particles over the cross-section (see Fig. 2) is homogeneous as well. The particles having their centre-of-masses inside the circle A, hereafter are referred to as the particles that "have to be sampled". That term and the corresponding quantity serve for the normalization, i.e., they allow the determination of the considered probabilities in the following.

The probability that a cloud particle is shattered, i.e., is withdrawn from the sampled population due to a collision with the probe inlet, strongly depends on the particle diameter $d$ with respect to the diameter of the inlet. For example, a particle with the diameter higher than the diameter $D$ of the inlet (i.e., the diameter of the $A$ circle on Fig. 2) is always shattered. The inlet diameter $D$ values are of $10 \mathrm{~mm}$ and of $40 \mathrm{~mm}$ for the Polar Nephelometer and the FSSP-300, respectively. The both values are large with respect to cloud-particles sizes. That is why the case $d>D$ is ignored in our model.

In order to illustrate the determination of the loss-process probability, we use in Fig. 2 the dashed $B$ and $C$ circles that are concentric with the $A$ circle. The diameters of $B$ and $\mathrm{C}$ are $D^{-}=D-d$ and $D^{+}=D+d$, respectively, and therefore depend on the diameter $d$ of a particle.

For a cloud particle of diameter $d$, there are three following possibilities:

(1) If the centre-of-mass of a particle falls inside the B circle, this particle goes into

\section{Probabilistic model of shattering effect on in-cloud measurements}

V. Shcherbakov et al.

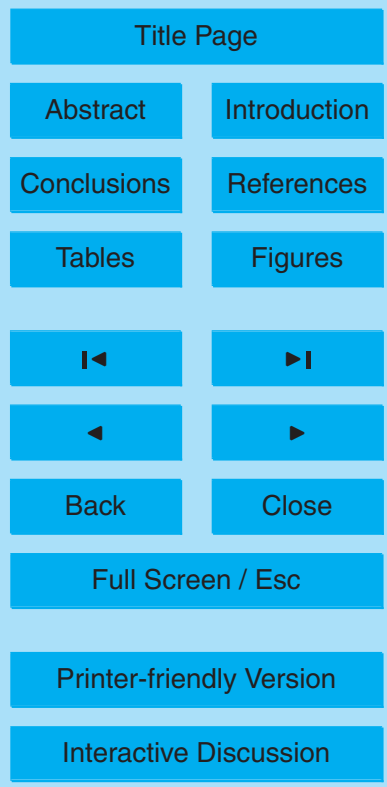


the inlet without interaction with the tip. Such a particle is referred to as a particle that has to be sampled and it is measured without shattering (case 1 on Fig. 2).

(2) If the centre-of-mass of a particle falls inside the ring between the circles $B$ and $A$, the particle collides with the inlet tip and shattering occurs. All subsequent fragments 5 will be sampled and measured. Such a particle is referred to as a particle that has to be sampled and it is shattered (case 2 on Fig. 2).

(3) If the centre-of-mass of the particle is inside the ring between the circles $A$ and $\mathrm{C}$, shattering happens. Because the centre-of-mass is outside of the circle $\mathrm{A}$, such a particle is referred to as a particle that must not be sampled and it is shattered (case 3 10 on Fig. 2).

The probability $p_{1}(d)$ that a cloud particle is measured without shattering (case 1 ) is proportional to the area $S_{B}$ of the circle $\mathrm{B}$. As it was mentioned above, we use for the normalization the area $S_{A}$ of the circle $A$. That is,

$p_{1}(d)=\frac{S_{B}}{S_{A}}=\frac{(D-d)^{2}}{D^{2}}, \quad d \leq D$

15 For $d>D, p_{1}(d)$ is set to zero. The probability $p_{1}(d)$ depends on the diameter of a particle and on the inlet diameter. It follows from Eq. (1) that the larger a particle is, the lower the probability $p_{1}(d)$ is.

The probability $p_{2}(d)$ that a particle has to be sampled and it is shattered (case 2 ) is proportional to the area $S_{2}$ of the ring between the circles $B$ and $A$; and it is inversely proportional to the area $S_{A}$ of the circle $A$ :

$p_{2}(d)=\frac{S_{2}}{S_{A}}=\frac{D^{2}-(D-d)^{2}}{D^{2}}=\frac{2 D d-d^{2}}{D^{2}}, \quad d \leq D$.

For $d>D, p_{2}(d)$ is set to zero. It is reasonable that $p_{1}(d)+p_{2}(d)=1$. It is seen from Eq. (2) that $p_{2}(d)$ tends to zero when the diameter of the particle tends to zero. That is, the smaller a particles is (with respect to the diameter $D$ of the inlet), the lower the shattering effect is.

\section{Probabilistic model of shattering effect on in-cloud measurements}

V. Shcherbakov et al.

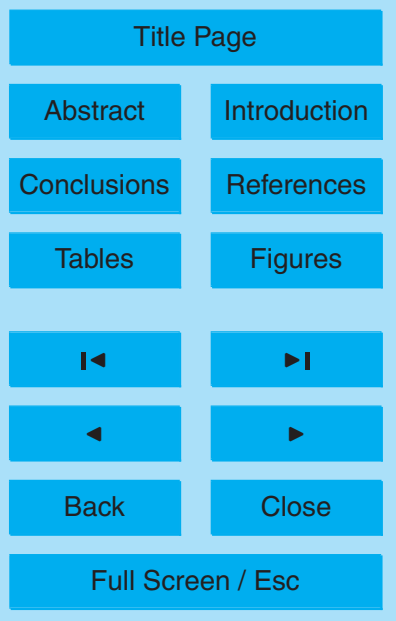

Printer-friendly Version

Interactive Discussion 
By the same way the coefficient $p_{3}(d)$ can be determined. The coefficient $p_{3}(d)$ is proportional to the probability that a particle must not be recorded and it is shattered (case 3 ). It is proportional to the area $S_{3}$ of the ring between the circles $C$ and $A$ :

$p_{3}(d)=\frac{S_{3}}{S_{A}}=\frac{(D+d)^{2}-D^{2}}{D^{2}}$.

5 Strictly speaking, the quantity $p_{3}(d)$ is not a probability because it can be greater than 1. Nevertheless, we consider it as a useful coefficient. It should be pointed out another time that Eqs. (1), (2) and (3) are the direct consequence of the homogeneity of the cloud-particle spatial distribution.

When a particle collides with the inlet tip (the cases 2 and 3 ), its fragments can go inside or outside the inlet. Generally, the proportion and the size distribution of fragments, which go inside, are governed by a number of characteristics and, first of all, they strongly depend on the design of the tip. As for a particle of a given diameter $d$, the proportion depends on the position of the centre-of-mass of the particle with regard to the A circle. Having no basis to estimate that proportion and for simplicity 15 sake, we assume that all fragments of case 2 enter into the inlet, and all fragments of the case 3 go outside the inlet. This assumption overestimates the proportion for case 2. That overestimation is partly compensated by the underestimation of the number of the fragments, which are related to the case 3 and could be sampled by the instrument.

We recall that the size distribution of particles that are measured by an instrument consists of two parts. The first part is the cloud particles that are not shattered; and the second one is the fragments of shattered particles. As it was mentioned above, the particle number size distribution $n_{1}(d)$ of the measured particles, which were not shattered, is not necessary equal to the actual size distribution $n_{0}(d)$ of the cloud particles. This feature is a consequence of the loss process. It follows from Eq. (1) that the size distribution $n_{1}(d)$ (case 1 ) is as follows:

$n_{1}(d)=n_{0}(d) p_{1}(d)=n_{0}(d) \frac{(D-d)^{2}}{D^{2}}$

\section{Probabilistic model of shattering effect on in-cloud measurements}

V. Shcherbakov et al.

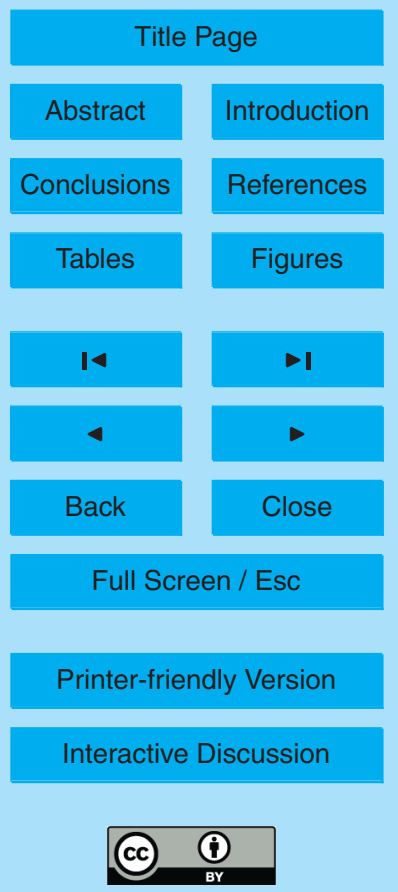


Equation (4) shows a non-linear relationship between $n_{1}(d)$ and $n_{0}(d)$. In other words, the larger the diameter $d$ is, the higher the difference between $n_{1}(d)$ and $n_{0}(d)$ is. And, it is important to keep in mind that the distribution $n_{1}(d)$ represents a fraction of particles, which are measured by an instrument.

5 The second part of particles, which are measured, consists of fragments of the shattered particles (case 2 in our model). Generally, the size distribution of the measured fragments depends on the size distribution of the shattered particles. Therefore we define the number size distribution $n_{2}(d)$ of the shattered particles, which produce all subsequent measured fragments. According to Eq. (2) $n_{2}(d)$ can be expressed as 10 follows:

$n_{2}(d)=n_{0}(d) p_{2}(d)=n_{0}(d) \frac{D^{2}-(D-d)^{2}}{D^{2}}$.

The relationship $n_{1}(d)+n_{2}(d)=n_{0}(d)$ is valid, it follows from the equality $p_{1}(d)+$ $p_{2}(d)=1$. It should be emphasized that the number size distribution $n_{2}(d)$ of the shattered particles is generally much smaller than the actual size distribution $n_{0}(d)$ of the cloud particles as we will see below.

\subsection{Effects on integral microphysical parameters}

When the particle size distribution $n_{0}(d)$ is known, Eqs. (4) and (5) serve to compute the integral parameters like the particle total concentration $N$, the extinction coefficient Ext, the ice water content IWC, and the effective diameter $d_{\text {eff }}$. For example, the extinction coefficient $E x t_{2}$ and the effective diameter $d_{\text {eff2 }}$ are computed on the basis of the size distribution $n_{2}(d)$.

As for the effect of fragments, additional simplifications and assumptions have to be introduced because the size distribution of the fragments depends on a number of physical processes and parameters, some of which are not known. We list some, but not all of them: the habit, size, and density of particles (Korolev and Isaac, 2005), the airspeed and the impact angle (Weber et al., 1998). Moreover, as indicated above the

\section{Probabilistic model of shattering effect on in-cloud measurements}

V. Shcherbakov et al.

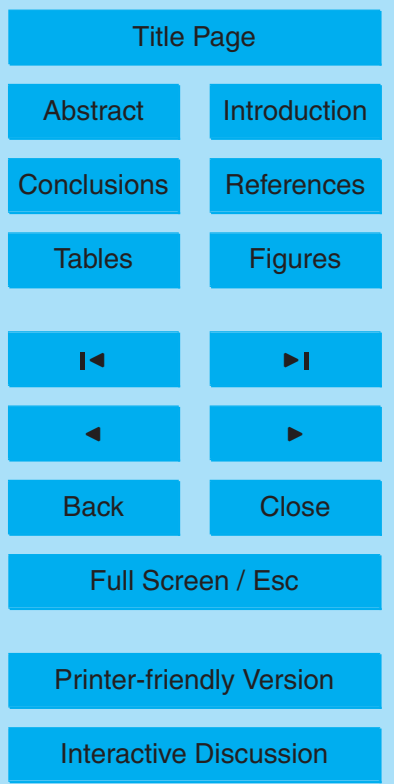


subsequent effects on the recorded and derived cloud properties depend on the spatial distribution of fragments over the inlet cross-section with respect to the effective sampling area of the probe. The Polar Nephelometer data are expected to be less sensitive to that feature while it is of particular importance for instruments with relatively small 5 sampling area regarding the inlet diameter, e.g., the FSSP. As previously indicated, for simplicity sake the spatial distribution of fragments is supposed to be homogeneous in our model.

Furthermore, it is assumed that conservation of mass holds true. That is, the total volume of the shattered particles (the case 2) is converted into fragments, which are 10 measured as cloud particles. Under the assumption that the spatial distribution of the fragments is homogeneous, conservation of mass leads to the property that the IWC of the fragments is equal to the IWC of shattered particles (conservation of IWC). This assumption could be justified from the estimates by Heymsfield (2007) who suggest that IWC from FSSP measurements could be overestimated by only $15 \%$ by shattering effects. It is self-evident that a shattering model cannot employ the fragment size distribution in an analytic or tabulated form. There are too many unknown parameters and characteristics. That is why only integral parameters of the size distribution are used in our model. Such a choice is based on the fact that the concept of the integral parameters works well in ice-clouds physics (see e.g., Heymsfield et al. 2006 and citations therein).

The effective diameter $d_{\text {eff }}$ of an ice particle population is composed of two variables: extinction (Ext) and the ice water content (IWC):

$d_{\mathrm{eff}}=\alpha \cdot \frac{I W C}{E x t}$,

where $\alpha$ is a coefficient. Generally, both Ext and IWC, as well as $\alpha$, are dependent upon the particle size distribution and the ice particle habit. For example, from Gayet et al. (2004) $\alpha$ is of 3.0 from with Ext and IWC expressed in $\mathrm{m}^{-1}$ and $\mathrm{g} \mathrm{m}^{-3}$, respectively. In our model, the coefficient $\alpha$ is supposed to be constant, i.e., it is of the same value

\section{ACPD}

$10,11009-11046,2010$

\section{Probabilistic model of shattering effect on in-cloud measurements}

V. Shcherbakov et al.

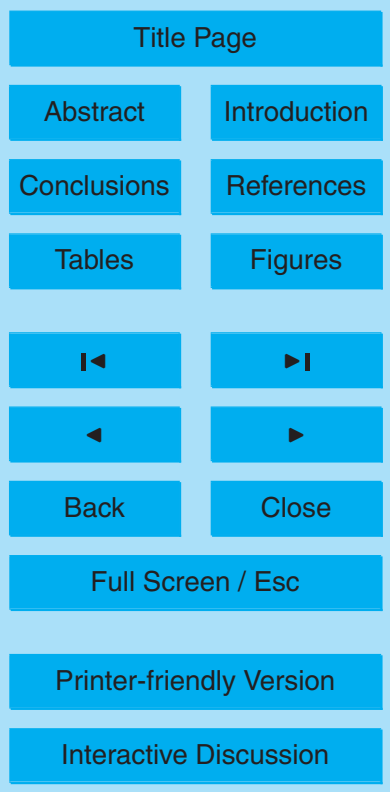


for cloud particles and fragments. It follows from Eq. (6) that :

$E x t=\alpha \cdot \frac{I W C}{d_{\mathrm{eff}}}$,

ACPD

i.e., when IWC is fixed, the extinction is inversely proportional to the effective diameter. In other words, the smaller the fragments of a given cloud particle, the higher their effect 5 on the measured extinction. If the conservation of IWC holds true, the key parameter is the effective diameter $d_{\text {eff } F R}$ of the fragments with respect to the effective diameter $d_{\text {eff2 }}$ of the shattered cloud particles; and the extinction coefficient $E x t_{F R}$ of the fragments can be expressed as follows:

$E x t_{F R}=E x t_{2} \frac{d_{\mathrm{eff} 2}}{d_{\mathrm{eff} F R}}$,

10 where $E x t_{2}$ is the extinction coefficient of the shattered particles (the case 2).

The Polar Nephelometer measures the scattering phase function of an ensemble of particles from a few micrometers to about $1 \mathrm{~mm}$ diameter. Thus, all assumptions taken together lead to the following value $E x t_{\text {mes }}$ of the extinction coefficient measured by the PN:

$15 E x t_{\mathrm{mes}}=E x t_{0}+E x t_{F R}-E x t_{2}$,

where $E x t_{0}$ is the actual extinction coefficient of the cloud particles. It follows from Eqs. (8) and (9) that the shattering effect can be written for the Polar Nephelometer in fraction terms as:

$\delta E x t_{P N}=\frac{E x t_{\mathrm{mes}}-E x t_{0}}{E x t_{0}}=\frac{E x t_{2}}{E x t_{0}}\left(\frac{d_{\mathrm{eff} 2}}{d_{\mathrm{eff} F R}}-1\right)$,

Considering now the FSSP, the size range of that instrument is typically from $2 \mu \mathrm{m}$ to $22 \mu \mathrm{m}$ with the series 300 used during cirrus studies (Gayet et al., 2004). This limited

Probabilistic model of shattering effect on in-cloud measurements

V. Shcherbakov et al.

Title Page

Abstract Introduction

Conclusions

Tables References Figures

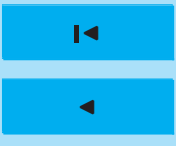
$>1$

Back

Close

Full Screen / Esc

Printer-friendly Version

Interactive Discussion 
size range must be considered for the estimation of the shattering effect on FSSP-300 measurements. For example, Eq. (9) is rewritten as:

$E x t_{\mathrm{mesFSSP}}=E x t_{\mathrm{OFSSP}}+E x t_{F R \mathrm{FSSP}}-E x t_{2 \mathrm{FSSP}}$,

where the subscript "FSSP" means that the corresponding values are computed for the 5 sampling size range of the FSSP-300 instrument. If the size of all fragments is within that range, the shattering effect on the extinction coefficient deduced from FSSP-300 data is expressed as follows:

$\delta E x t_{\mathrm{FSSP}}=\frac{E x t_{F R \text { FSSP }}-E x t_{2 \mathrm{FSSP}}}{E x t_{0 \mathrm{FSSP}}}=\frac{E x t_{2}}{E x t_{0 \mathrm{FSSP}}} \frac{d_{\text {eff } 2}}{d_{\text {eff } F R}}-\frac{E x t_{2 \mathrm{FSSP}}}{E x t_{0 \mathrm{FSSP}}}$,

It follows from Eq. (10) that the key parameters of the shattering effect on PN data are: $(i)$ the ratio $d_{\mathrm{eff} 2} / d_{\mathrm{eff} F R}$ of the effective diameters of the shattered particles and of the fragments, and (ii) the ratio $E x t_{2} / E x t_{0}$ of the extinction coefficients of the shattered particles and of the cloud particles. Concerning the FSSP, our simulations revealed that the second term on the right-hand side of Eq. (12) is, as a rule, negligibly small. Thus, the key parameters of the shattering effect $\delta$ Ext $t_{\mathrm{FSSP}}$ are the same. The difference is 15 that the extinction coefficient Ext ${ }_{0 \mathrm{FSSP}}$ should be used in the ratio $E x t_{2} / \mathrm{Ext}_{0 \mathrm{FSSP}}$.

The last part of this section deals with the shattering effect on the number concentration measured by the FSSP instrument. The effect is estimated under all assumptions discussed above. Let $N_{\text {OFSSP }}$ be the actual number concentration of cloud particles within the FSSP size range and $N_{\text {mesFSSP }}$ be the number concentration recorded by the instrument. Then, the shattering effect written in percentage terms is:

$\delta N_{\mathrm{FSSP}}=\frac{N_{\text {mesFSSP }}-N_{\text {OFSSP }}}{N_{\text {OFSSP }}}=\frac{N_{F R}-N_{2 \mathrm{FSSP}}}{N_{\text {OFSSP }}}$,

where $N_{\text {mesFSSP }}=N_{0 F S S P}+N_{F R}-N_{2 F S S P}, N_{F R}$ and $N_{2 F S S P}$ are the number concentrations of the fragments and of the shattered cloud particles, respectively. All magnitudes are computed only within the FSSP size range. In addition to Eq. (13), we employ the

Probabilistic model of shattering effect on in-cloud measurements

V. Shcherbakov et al.

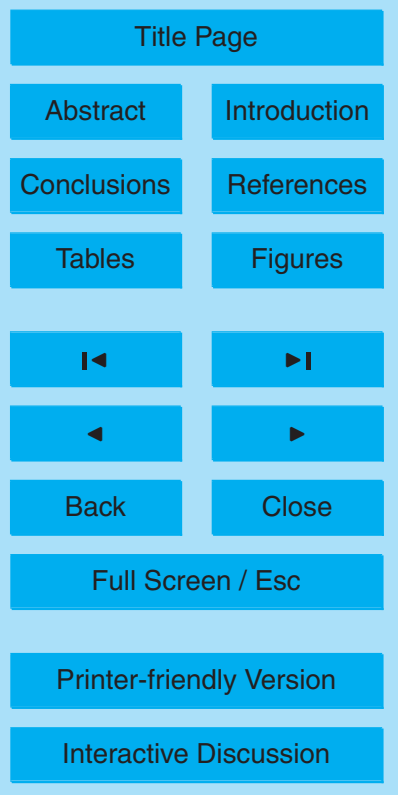

Interactive Discussion 
following relationship between the extinction coefficient Ext and the number concentration $N$ of particles (see, e.g., Korolev et al. 2001):

$E x t=\beta \cdot N \cdot d_{\text {eff }}^{2}$,

where $\beta$ is the coefficient, which is expressed as $\beta=\pi Q / 4$ for spherical particles; $Q$

5 is the extinction efficiency (equal to 2 according to the large particle approximation). In our model, the coefficient $\beta$ is supposed to have the same value for cloud particles and fragments. It follows from Eqs. (8), (13), and (14) that the shattering effect on the number concentration $\delta N_{\text {FSSP }}$ can be written as:

$\delta N_{\mathrm{FSSP}}=\frac{E x t_{2}}{E x t_{0 \mathrm{FSSP}}} \cdot \frac{d_{\mathrm{eff} 2}}{d_{\mathrm{eff} F R}} \cdot \frac{d_{\mathrm{effOFSSP}}^{2}}{d_{\mathrm{eff} F R}^{2}}-\frac{E x t_{2 \mathrm{FSSP}}}{E x t_{0 \mathrm{FSSP}}} \cdot \frac{d_{\mathrm{effOFSSP}}^{2}}{d_{\mathrm{eff} 2 \mathrm{FSSP}}^{2}}$.

10 As above, it is supposed that the size of all fragments is within the FSSP's sampling size range. It should be mentioned that the shattering effect is expressed by Eqs. (10), (12) and (15) in relative units, that is, the relationships are independent of the absolute value of the total concentration of cloud particles.

\section{Estimation of the effects of ice particle shattering on in-cloud measurements}

15 The model discussed above, treats of the shattering effect as a direct problem, i.e., all characteristics are computed on the basis of the size distribution $n_{0}(d)$ of cloud particles. On the other hand, all experimental data on cloud particles reported in the scientific literature are more or less affected by an instrument or a set of instruments. Thus, any case study must uses a size distribution that could already be affected by 20 the shattering. Nevertheless, experimental data provide opportunities to obtain quite reliable estimates and to assign key parameters that govern the shattering effect.

The results below are based on the data obtained during the INCA experiment (Ström et al. 2001) and reported by Shcherbakov et al. (2005). For comparison purposes, three following particle number size distributions were chosen. The particle size

Probabilistic model of shattering effect on in-cloud measurements

V. Shcherbakov et al.

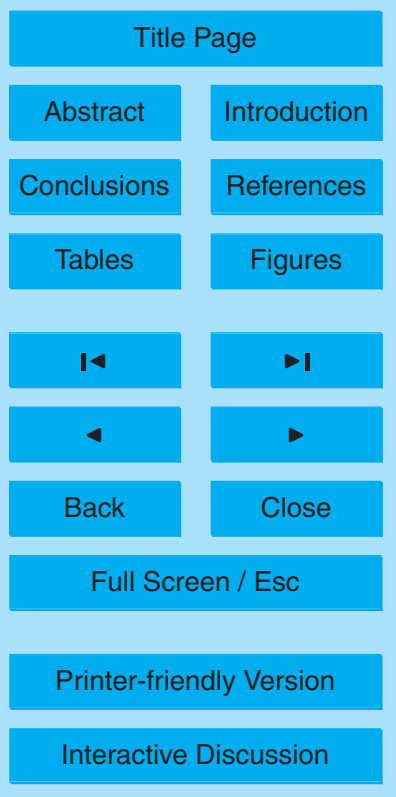

Interactive Discussion 
distribution labelled D2 and represented on Fig. 3 is the average cirrus ice-crystal size distribution computed for the dataset, which was recorded during the field campaign performed at midlatitudes in the Southern Hemisphere. The particle size distributions D1 and D3 (see Fig. 3) were generated using the technique of principal component 5 analysis (PCA) (see details in Shcherbakov et al., 2005). We recall that the PCA provides the possibility of reproducing almost all the variability of a dataset with reasonably good accuracy while considering only a few principal components. The number size distributions are shown on Figure 3 and they are considered as $n_{0}(d)$ functions in subsequent calculations. The size ranges from 3.0 to $21.8 \mu \mathrm{m}$ and from 22.5 to $800 \mu \mathrm{m}$ 10 correspond to the FSSP-300 and to the PMS 2D-C data, respectively. We note in passing that the jump in the concentration from the FSSP and the 2D-C on Fig. 3 may be due to shattering effects on FSSP measurements and/or 2D-C problems at small size due to electronic probe response (Strapp et al., 2001). We consider in a first guess these size distributions as representative in order to assess shattering effects on FSSP and Polar Nephelometer measurements. The corresponding values of the integral parameters are shown on Table 1 and they agree well with the data reported by Gayet et al. (2006). It should be mentioned that the effective diameter $d_{\text {effo }}$ values vary from $36 \mu \mathrm{m}$ to $89 \mu \mathrm{m}$ (see Table 1), that is, the proportion of large particles varies within a large range.

20 The number size distributions $n_{1}(d)$ and $n_{2}(d)$ were computed according to Eqs. (4) and (5) for the inlet diameter $D$ values of $10 \mathrm{~mm}$ and of $40 \mathrm{~mm}$ for the Polar Nephelometer and the FSSP-300, respectively. The both values of the inlet diameter are large with respect to cloud-particles sizes. This explains the fact that the size distributions of actual cloud particles $\left(n_{0}(d)\right)$ and non-shattered particles $\left(n_{1}(d)\right)$ are close together on 25 Fig. 3 and cannot be clearly distinguished in log-log scale.

The size distributions $n_{2}(d)$ of the shattered particles, computed for the PN inlet diameter $D=10 \mathrm{~mm}$, are shown on Fig. 3 as well. We note in passing that the same colour convention is used for the size distributions $n_{0}(d)$ and $n_{2}(d)$. There is an analogy between $n_{2}(d)$ and $n_{0}(d)$ because $n_{2}(d)$ is directly related to $n_{0}(d)$ by Eq. (5). At

\section{Probabilistic model of shattering effect on in-cloud measurements}

V. Shcherbakov et al.

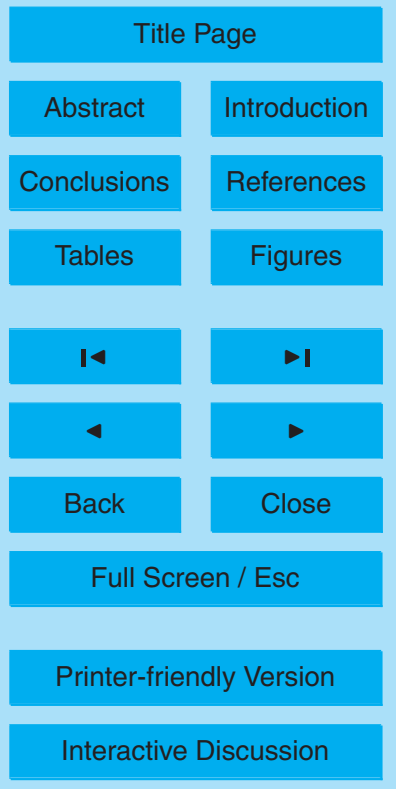


the same time, the proportion of the large particles (see the effective diameter values in Table 3 ) is much higher in $n_{2}(d)$ because the probability $p_{2}(d)$ increases with the particle diameter $d$. The main properties of the distributions $n_{2}(d)$, computed for the FSSP-300 inlet diameter $D=40 \mathrm{~mm}$, are the same. The difference is in the absolute

5 values that are about four times lower because the FSSP inlet diameter is four times larger compared to the PN geometry.

\subsection{Effect of the $E x t_{2} / E x t_{0}$ ratio}

In order to quantify the shattering effect in reference to the cloud particles, we will first deal with the integral parameters of particles, which are shattered and produce 10 measured fragments (the case 2), relative to the corresponding values of the actual cloud particles. We recall that $n_{2}(d)$, which is obtained from Eq. (5), is not the size distribution of fragments, but addresses the shattered cloud particles. The particle total concentrations $\left(N_{0}\right.$ and $\left.N_{2}\right)$, the extinction coefficient $\left(E x t_{0}\right.$ and $\left.E x t_{2}\right)$, and the ice water content $\left(I W C_{0}\right.$ and $\left.I W C_{2}\right)$ were computed on the basis of the number size distributions $\left(n_{0}(d)\right.$ and $\left.n_{2}(d)\right)$ according to well-known relationships (see, e.g., Korolev et al., 2001).

Table 2 shows the percentages $(\delta)$ of the shattered particles to actual particles expressed in terms of particle concentration, extinction and ice water content for the Polar Nephelometer and FSSP inlets. We recall that on all figures and tables, the notations D1, D2, and D3 correspond to the three size distributions $n_{0}(d)$ shown on Fig. 3 . For example the percentages are $0.19 \%, 1.34 \%$ and $3.81 \%$ for the particle concentration, extinction and ice water content, respectively, with the Polar Nephelometer inlet. As expected, the values for the FSSP-300 instrument are lower than those for the Polar Nephelometer. As already indicated, the four-fold increase of the inlet diameter re25 sulted in a four-times decrease of the integral parameters of the shattered particles. These relative values depend on the size distributions of cloud particles, i.e., they increase with increasing $d_{\text {effo }}$. We recall that the total volume (or IWC) of the shattered particles is assumed to be converted into fragments, which are measured as cloud

\section{Probabilistic model of shattering effect on in-cloud measurements}

V. Shcherbakov et al.

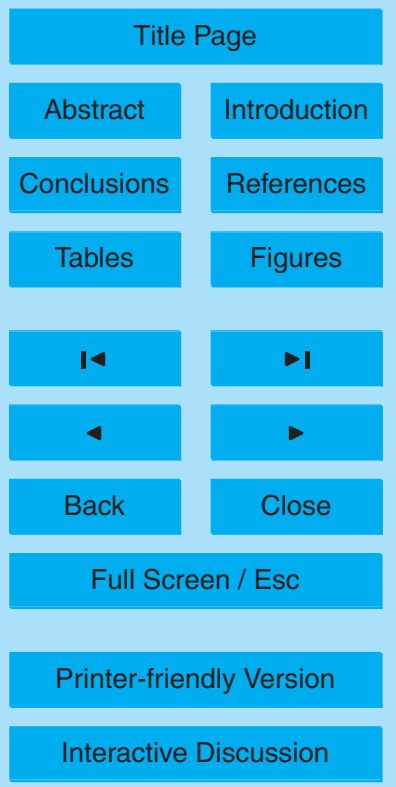


particles. The increase of the ratio $\delta / W C(\%)=100 \cdot I W C_{2} / I W C_{0}$ with $d_{\text {effo }}$ in Table 2 means that the higher the proportion of the large cloud particles is, the higher the shattering effect is, all other factors being the same.

As follows from Eq. (10), the ratio $\delta E x t=E x t_{2} / E x t_{0}$ is one of the key parameters 5 that govern the shattering effect on PN data. At first glance the values of $\delta E x t$ would seem small. Nevertheless, we show below that such values would have a significant importance in shattering effects on measurements.

\subsection{Effects of the effective diameter of the particle fragments and of large particles}

10 Another key parameter of the shattering effect is the ratio $d_{\mathrm{eff} 2} / d_{\mathrm{eff} F R}$. The values of the effective diameter $d_{\text {eff2 }}$ of the shattered particles (the case 2) are reported in Table 3. The first line of numbers of Table 3 corresponds to the size distributions $n_{2}(d)$ shown on Fig. 3. The effective diameter $d_{\text {eff2 }}$ is much larger than $d_{\text {effo }}$ due to the increased proportion of large particles (192 $\mu \mathrm{m}$ against $68 \mu \mathrm{m}$ for the Polar Nephelometer inlet).

15 It is seen that $d_{\text {eff2 }}$ depends on the size distribution of cloud particles and it is less sensitive to the inlet diameter.

In contrast to $d_{\text {eff } 2}$, the assessment of the effective diameter $d_{\text {eff } F R}$ is the challenge since microphysical parameters of fragments are not sufficiently studied to date. There is little information on this matter. Vidaurre and Hallett (2009) concluded that the impact 20 kinetic to surface energy ratio serves as a useful breakup criterion and indicates that both drops and ice crystals larger than a few microns often break apart if they happen to impact on any aircraft-mounted instrument. And, they showed that an ice crystal of a few hundreds microns diameter can be broken up into hundreds of fragments. Moreover, Vidaurre and Hallett (2009) speculated that a total conversion of impact 25 kinetic energy into surface energy could be achieved by breaking the entire crystal into hexagonal columns of 30-nm dimension. On the other hand, Heymsfield et al. (2007, Appendix A) found that that the mass-weighted mean diameters were around 14-16 $\mu \mathrm{m}$ for particles recorded by the Cloud and Aerosol Spectrometer (CAS) in the conditions

\section{Probabilistic model of shattering effect on in-cloud measurements}

V. Shcherbakov et al.

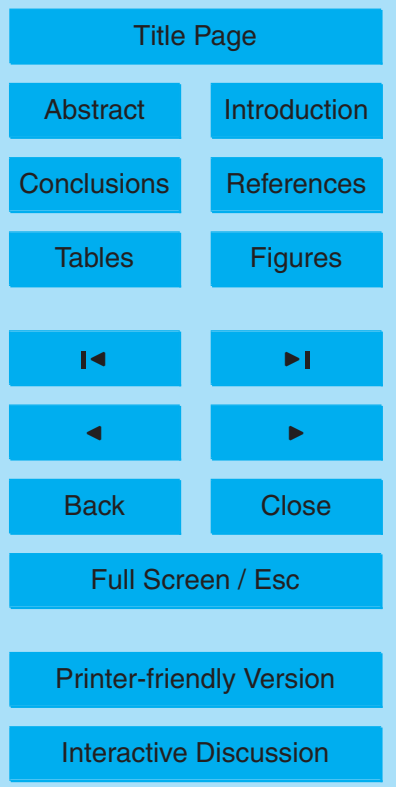


that were favourable to the shattering. As a consequence of such a large uncertainty, we estimated the shattering effect on integral parameters for a set of values of $d_{\text {eff } F R}$ that are in the most expected size range.

\subsubsection{Polar Nephemometer measurements}

5 The effects on the extinction coefficient derived from the Polar Nephelometer data, were computed according to Eq. (10). The estimated values of $\delta \operatorname{Ext}_{P N}$ are shown on Fig. 4 as function of $d_{\text {eff } F R}$ for the three considered size distributions (D1, D2 and D3). As expected, the results highlight that ice particle shattering leads to the overestimation of the extinction coefficient. The effect is very sensitive to the value of the effective diameter of the fragments $\left(d_{\mathrm{eff} F R}\right)$ and it depends on the actual particle size distributions (D1 to D3), i.e. on the proportion of the large cloud particles. For example, with the distribution D2 (characterized by the effective diameter of $68 \mu \mathrm{m}$ see Table 1 ), $\delta$ Ext $_{P N}$ increases from $12 \%$ to $50 \%$ with $d_{\text {eff } F R}$ decreasing from $20 \mu \mathrm{m}$ to $5 \mu \mathrm{m}$. The effects of the proportion of large particles are exemplified on Fig. 5 (upper panel). For a given effective diameter of the particle fragments $\left(d_{\mathrm{eff} F R}=10 \mu \mathrm{m}\right.$ for instance), the overestimation factor $\left(\delta E x t_{P N}\right)$ increases from $9 \%$ to $37 \%$ as the effective diameter of the actual particle size distribution ( $\left.d_{\text {effo }}\right)$ increases from $36 \mu \mathrm{m}$ to $89 \mu \mathrm{m}$ respectively.

\subsubsection{FSSP-300 measurements}

The shattering effects on FSSP-300 data were computed according to Eqs. (12) and

(14). The values of $\delta N_{\mathrm{FSSP}}$ and $\delta E x t_{\mathrm{FSSP}}$ are given on Figure 6 as a function of $d_{\mathrm{eff} F R}$ for the three considered size distributions (D1, D2 and D3). As with the Polar Nephelometer, the results show that the both parameters are very sensitive to the values of the effective diameter of the fragments and to the proportion of the large cloud particles. For example, considering the size distribution D2 $\left(d_{\text {effo }}=68 \mu \mathrm{m}\right)$ with a fragment effective diameter $\left(d_{\text {effFR }}\right)$ of $10 \mu \mathrm{m}$ the particle concentration (see Fig. 6a) and the extinction (see Fig. 6b) are overestimated by $30 \%$ and $17 \%$ respectively. With $d_{\text {effFR }}=$

\section{Probabilistic model of shattering effect on in-cloud measurements}

V. Shcherbakov et al.

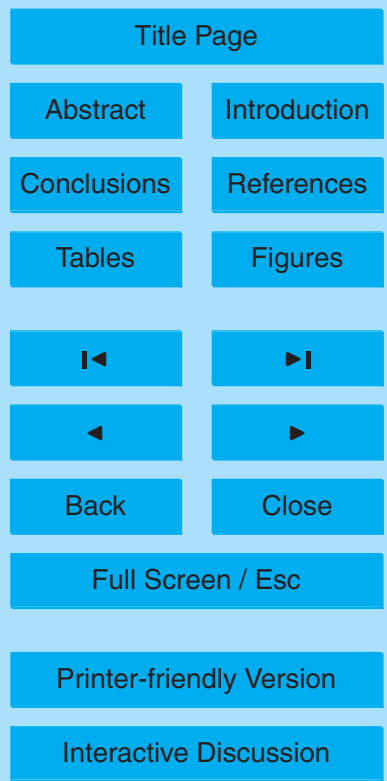


$5 \mu \mathrm{m}$, these values increase to $235 \%$ and $34 \%$ respectively. If the effective diameter of the fragments is of $5 \mu \mathrm{m}$, the errors on the particle concentration also increase significantly from $50 \%$ to $550 \%$ with the proportion of the large cloud particles (D1 $d_{\text {effo }}=$ $36 \mu \mathrm{m}$ and $\mathrm{D} 3 d_{\text {effo }}=89 \mu \mathrm{m}$, respectively). This result is in support of the conclusion 5 that shattering may result in large overcounting of ice particles measured by FSSP in midlatitude cirrus by factor of 2 to 5 (Field et al. 2003). As for extinction, the results on Fig. 5 (bottom panel) show a similar feature regarding the Polar Nephelometer but with smaller errors for $d_{\mathrm{eff} F R}=5 \mu \mathrm{m}$.

It is interesting to highlight that the extinction overestimations are of the same orders 10 for the Polar Nephelometer and the FSSP (25\% and 20\% respectively) for identical simulated conditions $\left(d_{\text {eff } F R}=10 \mu \mathrm{m}\right.$ and $d_{\text {eff }}=68 \mu \mathrm{m}$, D2). This could nicely explain the very good consistency of comparison results between extinctions calculated from two different techniques (combination of FSSP-300 and CPI probes and Polar Nephelometer) even in presence of large ice crystals in cirrus clouds where shattering is 15 likely occurring with a similar efficiency on the two instruments (Mioche et al., 2010, see their Fig. 7). This consistency could be fortuitous but may also give an indication that the ice water content (IWC) of fragments over the sampling cross section of the FSSP-300 is close to the IWC of the shattered particles.

Furthermore, Mioche et al. (2010) compared CALIOP and airborne PN co-located observations in terms of extinction coefficient in different cirrus cloud situations. Very good agreements were observed when small irregularly-shaped ice crystals $\left(d_{\text {eff }} \sim 20-\right.$ $40 \mu \mathrm{m}$ ) are present, while systematic larger PN extinction values (with regard to CALIOP data) were evidenced for cirrus with large irregularly-shaped ice crystals $\left(d_{\text {eff } 0} \sim 80 \mu \mathrm{m}\right)$. Assuming the CALIOP data to be unbiased, the shattering of larger ice 25 crystals seems to be a plausible explanation for the PN large extinction values ( $38 \%$ of overestimation). If this hypothesis holds true for the PN overestimation of $38 \%$ and for an actual effective diameter of $80 \mu \mathrm{m}$, the effective diameter of the fragments would be around $10 \mu \mathrm{m}$ following the results on Fig. 5a. With these inputs the overestimation of the FSSP extinction would also be about $30 \%$ (confirming the results above) and the

\section{Probabilistic model of shattering effect on in-cloud measurements}

V. Shcherbakov et al.

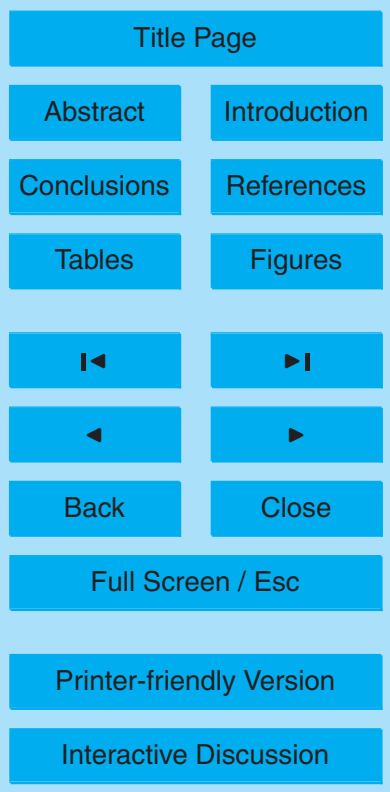

\section{8}


error on the measured particle concentration would be about $70 \%$ (see Fig. 6a).

Considering that the mean effective diameter $\left(d_{\text {effo }}\right)$ of $68 \mu \mathrm{m}$ (see Table 1 and size distribution D2 on Fig. 3) is representative of the observations made during INCA, the above estimated errors on PN and FSSP measurements are, on the average, of the

5 same order of the usual random uncertainties (i.e., $85 \%$ and $75 \%$ on the extinction and the particle concentration respectively, see Table 1 in Gayet et al., 2002). Therefore most of the published results on mid-latitude cirrus during INCA would be reliable within the measurements accuracies. Only about $20 \%$ of the observations made at temperatures higher than $-40^{\circ} \mathrm{C}$ could have greater shattering errors due to subse10 quent larger effective diameters of cloud particles (Gayet et al., 2004).

As for previous results obtained in contrails (Febvre et al., 2009), we believe that the observations are not affected by shattering effects because small particles were measured with effective diameter smaller than $25 \mu \mathrm{m}$.

\section{Discussion and practical application}

\section{4.1 Discussion}

It was pointed out above that our model is simple, it is wholly probabilistic, and a number of simplifications and assumptions were used. The validity of the assumptions is under question. In this section, we discuss point by point the possible consequences.

(i) The spatial distribution of all fragments is supposed to be homogeneous, it doesn't depend on the size of a cloud particle or of a fragment, and there is no any correlation. Generally, the spatial distribution of the fragments should be inhomogeneous and it should depend on the distances (i) between the sampling volume and the inlet inner-edge and (ii) between the sampling volume and the leading edge of the inlet. In addition, it should depend on the inlet design, on the airspeed through the probe, on the change in the flow field due to the probe itself, and on physical characteristics of cloud particles. The PN data are expected to be insensitive to that simplification be-

\section{Probabilistic model of shattering effect on in-cloud measurements}

V. Shcherbakov et al.

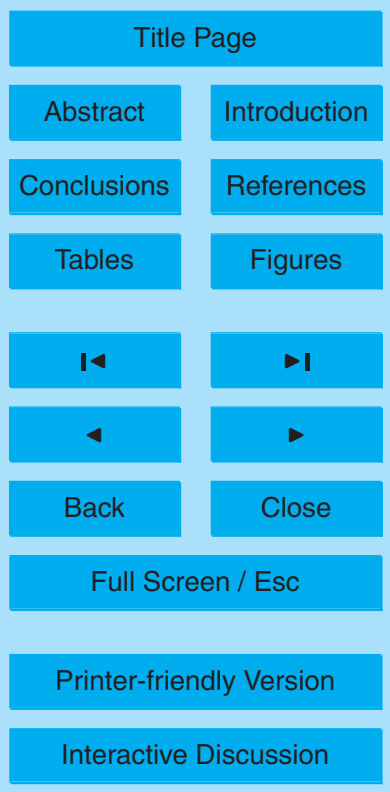

\section{9}


cause the PN sampling area is large and thus most of fragments are recorded. To the contrary, the FSSP sampling area is small with reference to the inlet diameter. It might be expected that most of fragments go preferentially near the inlet border and miss the sampling volume. In this case, our assumption leads to overestimation of the shattering 5 effect. At the same time, it could lead to underestimation, because we cannot exclude that the fragments go preferably along the probe axis due to the lateral forces involved in the breakup of a cloud particle. If experimental data demonstrate spatial inhomogeneous distribution of fragments, a coefficient, which relates IWC of the fragments to IWC of the shattered particles, should be assumed.

10 (ii) The width of the tip of the inlet is assumed to be a negligibly small quantity. Largewall leading edges may significantly increase the shattering effect. Thus, it should be highly recommended to optimize the inlet design of FSSP instruments.

(iii) All particles in a sampled cloud and all fragments are supposed to be spheres. That assumption is widely used in our model. Ice breakup mechanisms may occur likely depending on the ice particle structure (dense graupels or delicate branched crystals).

(iv) The fragments, which go inside the inlet, originate from and only from the particles that have to be sampled and are shattered (case 2). Generally, some fragments of particles of the case 2 can go outside the inlet, and some fragments of the case 3 can go inside the inlet.

(v) The model is probabilistic and physical processes are not considered. It could be expected that airflow modelling could improve the assessment of the shattering effect. In our opinion, the most important question to be addressed by airflow modelling is the spatial distribution of fragments inside the inlet. Of course, the modelling should be based on a reliable model of breakup of ice particles.

(vi) It is assumed that the conservation of mass holds true. That is, the total volume of the shattered particles is transformed into fragments, which are recorded as cloud particles. This assumption seems to be quite reliable for the Polar Nephelometer because it measures the cloud property of an ensemble of particles ranged from a few

\section{Probabilistic model of shattering effect on in-cloud measurements}

V. Shcherbakov et al.

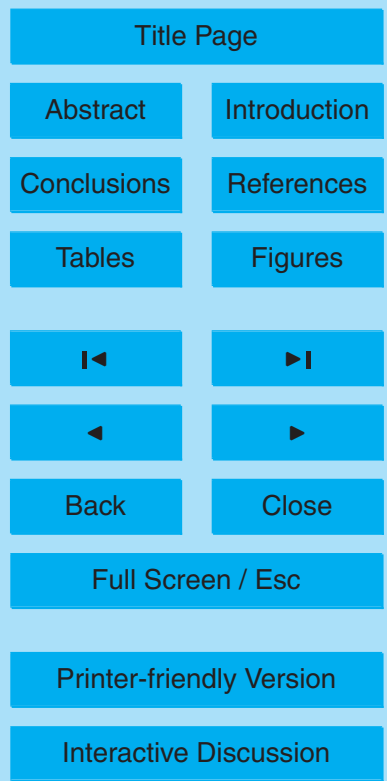


microns to $1 \mathrm{~mm}$. As for the FSSP instrument, the fragments, which have a size beyond the sampling range (2-22 $\mu \mathrm{m}$ for the series 300$)$, do not affect the recorded data. Thus, a portion of the mass of the shattered particles is definitively lost and this decreases the shattering effect.

5 (vii) In our estimations, we employed experimental data that are already somewhat affected. Generally, the shattering decreased the fraction of large particles in favour of the small ones, and in turn this somewhat decreased the estimated values.

\subsection{Practical application}

As it was pointed out above, our model treats the shattering effect as a direct problem, 10 that is, the equations employ an unaffected size distribution of cloud particles. On the other hand, there is an obvious need to quantify the shattering effect on the basis of measured data.

Our simulations with a thorough analysis of the Eqs. (10), (12), and (15) revealed that the principal contribution to the shattering is from the size range of large particles.

15 Thus, a size distribution, which is measured by 2D-C, CPI or 2D-S probes, can be used for rough assessments. In absolute units, the shattering effect on Polar Nephelometer and FSSP data can be expressed as follows:

$\Delta E x t_{P N}=E x t_{2} \cdot\left(\frac{d_{\mathrm{eff} 2}}{d_{\mathrm{eff} F R}}-1\right)$

$\Delta N_{\mathrm{FSSP}}=\frac{I W C_{2}}{(\pi / 6) \rho d_{\mathrm{eff} F R}^{3}}$,

20 $\Delta E x t_{\mathrm{FSSP}}=\alpha \cdot \frac{I W C_{2}}{d_{\mathrm{eff} F R}}$,

where $\rho$ is the ice density, $\alpha$ is a coefficient (see Eq. 6). The values of $E x t_{2}, I W C_{2}$, and $d_{\text {eff2 }}$ are computed for the size distribution $n_{2}(d)$. The size distribution $n_{2}(d)$, in

\section{Probabilistic model of shattering effect on in-cloud measurements}

V. Shcherbakov et al.

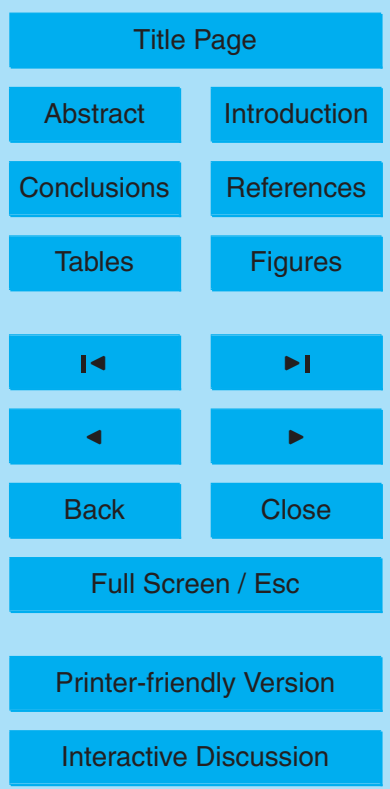

Interactive Discussion 
its turn, is calculated using Eq. (5), where $n_{0}(d)$ is the size distribution measured by 2D-C or 2D-S probe. Equations (17) and (18) were obtained from Eqs. (12) and (15) by neglecting small quantities, i.e., the second terms in the right-hand side.

If one deals with data measured by a FSSP instrument having the usual inlet design, 5 the value $C_{2 D, F S S P} \cdot I W C_{2 D-C}$ should be used instead $I W C_{2}$ in Eqs. (17) and (18), where $I W C_{2 D-C}$ is the ice water content of the size distribution $n_{0}(d)$ measured by 2D-C probe. $C_{2 D, F S S P}$ is an empirically derived-shattering coefficient; the basis assumption being that large particles shatter and increase the mass (IWC) or extinction (Ext) of ice in the probe measurements (see details in Heymsfield, 2007).

10 At the same time, that coefficient should depend on the effective diameter of $n_{0}(d)$ because the larger particles are, the higher the probability of the breakup is.

\section{Conclusions}

We present in this paper a probabilistic model of the effects of ice particle shattering on in-cloud measurements performed with instruments designed with inlets which have circular cross-section. The model provides rough estimates on microphysical measurements and assigns the key parameters that govern the efficiency of ice particle shattering. The model disclosed for the first time that not only cloud IWC governs the shattering effect, but a number of other factors as well. Due to the model we specified the priority factors such as the effective diameter of fragments, the effective diameter of shattered cloud particles, and the spatial distribution of the fragments inside the FSSP inlet.

The results show that experimental data are less affected by the shattering for clouds that have a lower proportion of large particles and confirm the results from previous studies (Field et al., 2003, Heymsfield, 2007, McFarquhar et al. 2007). The effects on the derived integral parameters are very sensitive to the effective diameter of the fragment particles and to the proportion of the large cloud particles, i.e., to the effective diameter of cloud particles. The smaller fragments of a given cloud particle are, the

\section{Probabilistic model of shattering effect on in-cloud measurements}

V. Shcherbakov et al.

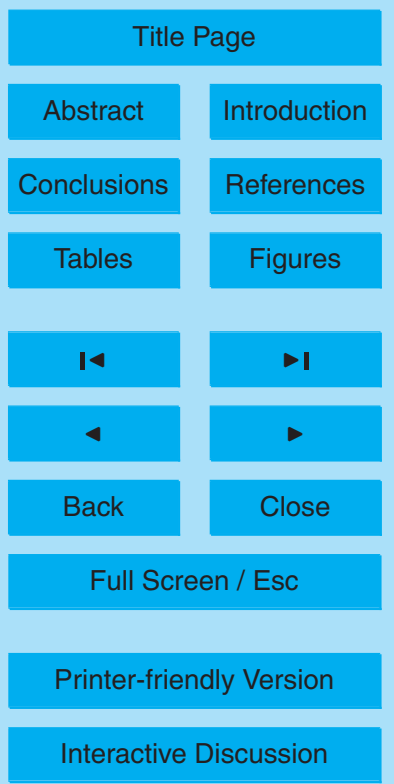

11032 
higher their effect is. It is expected that the effective diameter of fragments depends on the inlet design and on the habit, size, and density of cloud particles. A reliable model of breakup of an ice particle is sorely needed. The airspeed should also play a key part in that model.

$5 \quad$ Concerning the Polar Nephelometer measurements, the ice particle shattering leads to the overestimation of the extinction coefficient. For example for a given distribution with an effective diameter of $68 \mu \mathrm{m}$ and with a fragment effective diameter of $10 \mu \mathrm{m}$ the extinction is overestimated by $25 \%$. With larger particles $\left(d_{\text {eff }}=89 \mu \mathrm{m}\right)$ the error increases up to $37 \%$.

10 As for the FSSP-300 instrument, with the same conditions the extinction coefficient is overrated by $17 \%$ and the number particle concentration is overestimated by $30 \%$. It is interesting to underline that the extinction overestimations above are of the same orders for the two instruments. This could explain the very good consistency of comparison results between extinctions calculated from two different techniques (FSSP-300

15 and Polar Nephelometer) even in presence of large ice crystals in cirrus clouds where shattering is likely occurring with a similar efficiency on the two instruments.

Most of the published results on mid-latitude cirrus during INCA would be reliable within the measurements accuracies. Only observations made at temperatures higher than $-40^{\circ} \mathrm{C}$ could have greater shattering errors due to subsequent larger effective diameters of cloud particles. As for previous results obtained in contrails (Febvre et al., 2009), the observations are likely not affected by shattering effects because small particles were measured.

The discussion of the results points out the main hypothesis which may seriously limit the reliability of our modelling results. Nevertheless, the magnitudes of the errors on extinction and particle concentration are of the same orders of those reported in the literature from experimental assessments. Some of the hyphothesis could be verified from oriented experiments for instance by using cloud wind tunnels with controlled conditions for the assessment of different inlet designs, airspeed, range of particle size distributions, and so on.

\section{Probabilistic model of shattering effect on in-cloud measurements}

V. Shcherbakov et al.

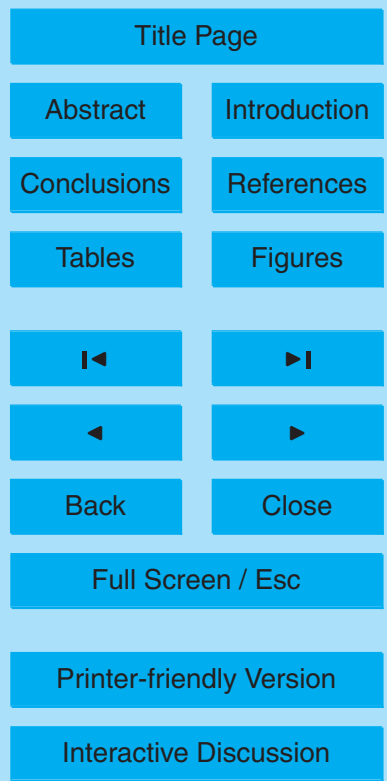


Acknowledgements. This work was funded by the Centre National d'Etudes Spatiales (CNES) and by the Institut Polaire Français Paul Emile Victor (IPEV). This work was funded by a grant from a CNRS/INSU program. We acknowledge C. Gourbeyre and J.-F. Fournol (LaMP) for their active participation to the airborne experiments A. Minikin (DLR) for fruitful discussions.

\section{ACPD}

10, 11009-11046, 2010

\section{Probabilistic model of shattering effect on in-cloud measurements}

Institut national des sciences de I'Univers

The publication of this article is financed by CNRS-INSU.

\section{References}

Baker, B., Mo, Q., Lawson, R. P., Korolev, A., and O'Connor, D.: Drop size distributions and the lack of small drops in RICO rain shafts, J. Appl. Meteorol. Clim., 48, 616-623, 2009.

Baumgardner, D., Dye, J. E., Gandrup, B. W., and Knollenberg, R. G.: Interpretation of measurements made by the Forward Scattering Spectrometer Probe (FSSP-300) during the airborne arctic stratosphere expedition, J. Geophys. Res., 97(D8), 8035-8046, 1992.

Febvre, G., Gayet, J.-F., Minikin, A., Schlager, H., Shcherbakov, V., Jourdan, O., Busen, R., Fiebig, M., Kärcher, B., and Schumann, U.: On optical and microphysical characteristics of contrails and cirrus, J. Geophys. Res., 114, D02204, doi:10.1029/2008JD010184, 2009.

Field, P. R., Wood, R., Brown, P. R. A., Kaye, P. H., Hirst, E., and Greeaway, R.: Ice particle interarrival times measured with a fast FSSP, J. Atmos. Ocean. Tech., 20, 249-261, 2003.

Field, P. R., Heymsfield, A. J., and Bansemer, A.: Shattering and interarrival times measured by optical array probes in ice clouds, J. Atmos. Ocean. Techn., 23, 1357-1371, 2006.

Gardiner, B. A. and Hallett, J.: Degradation of in-cloud Forward Scattering Spectrometer Probe measurements in the presence of ice crystals, J. Atmos. Ocean. Tech., 2, 171-180, 1985.

Garrett, T. J.: Comments on "Effective radius of ice cloud particle populations derived from aircraft probes", J. Atmos. Ocean. Tech., 24, 1492-1503, 2007.
V. Shcherbakov et al.

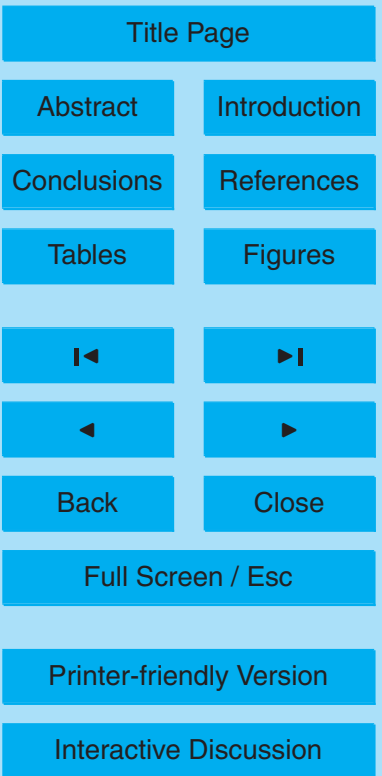


Gayet, J.-F., Febvre, G., and Larsen, H.: The reliability of the PMS FSSP in the presence of small ice crystals, J. Atmos. Ocean. Tech., 13, 1300-1310, 1996.

Gayet, J.-F., Crépel, O., Fournol, J.-F., and Oshchepkov, S.: A new airborne Polar Nephelometer for the measurements of optical and microphysical cloud properties. Part I: Theoretical

5 design, Ann. Geophys., 15, 451-459, 1997, http://www.ann-geophys.net/15/451/1997/.

Gayet, J.-F., Auriol, F., Minikin, A., Ström, J., Seifert, M., Krejci, R., Petzold, A., Febvre G., and Schumann, U.: Quantitative measurement of the microphysical and optical properties of cirrus clouds with four different in situ probes: Evidence of small ice crystals, Geophys. Res. Lett., 29(24), 2230, doi:10.1029/2001GL014342, 2002.

10 Gayet, J.-F., Ovarlez, J., Shcherbakov, V., Ström, J., Schumann, U., Minikin, A., Auriol, F., Petzold, A., and Monier, M.: Cirrus cloud microphysical and optical properties at southern and northern midlatitudes during the INCA experiment, J. Geophys. Res., 109, D20206, doi:10.1029/2004JD004803, 2004.

Gayet, J.-F., Shcherbakov, V., Mannstein, H., Minikin, A., Schumann, U., Ström, J., Petzold, A., 15 Ovarlez, J., and Immler, F.: Microphysical and optical properties of midlatitude cirrus clouds observed in the southern hemisphere during INCA, Quart. J. Roy. Meteor. Soc., 132(621), 2719-2748, 2006.

Heymsfield A. J., Schmitt, C., Bansemer, A., Van Zadelhoff, G.-J., McGill, M. J., Twohy, C., and Baumgardner, D.: Effective radius of ice cloud particle populations derived from aircraft 20 probes. J. Atmos. Ocean. Technol., 23, 361-380, 2006.

Heymsfield, A. J.: On measurements of small ice particles in clouds, Geophys. Res. Lett., 34, L23812, doi:10.1029/2007GL030951, 2007.

Heymsfield A. J., Schmitt, C., Bansemer, A., Van Zadelhoff, G.-J., McGill, M. J., Twohy, C., and Baumgardner, D.: Responses to comments on "Effective radius of ice cloud particle populations derived from aircraft probes" by Heymsfield et al, 2006. J. Atmos. Ocean. Technol., 24, 1511-1518, 2007.

Heymsfield, A. J., Bansemer, A., Heymsfield, G., and Fierro, A. O.: Microphysics of maritime tropical convective updrafts at temperatures from $-20^{\circ}$ to $-60^{\circ}$, J. Atmos. Sci., $66,3530-$ 3562, 2009.

30 Hudson, J. G. and Frisbie, P. R.: Cloud condensation nuclei near marine stratus, J. Geophys. Res., 96, 20795-20808, 1991.

Jensen, E. J., Lawson, P., Baker, B., Pilson, B., Mo, Q., Heymsfield, A. J., Bansemer, A., Bui, T.P., McGill, M., Hlavka, D., Heymsfield, G., Platnick, S., Arnold, G. T., and Tanelli, S.: On the

\section{ACPD}

10, 11009-11046, 2010

\section{Probabilistic model of shattering effect on in-cloud measurements}

V. Shcherbakov et al.

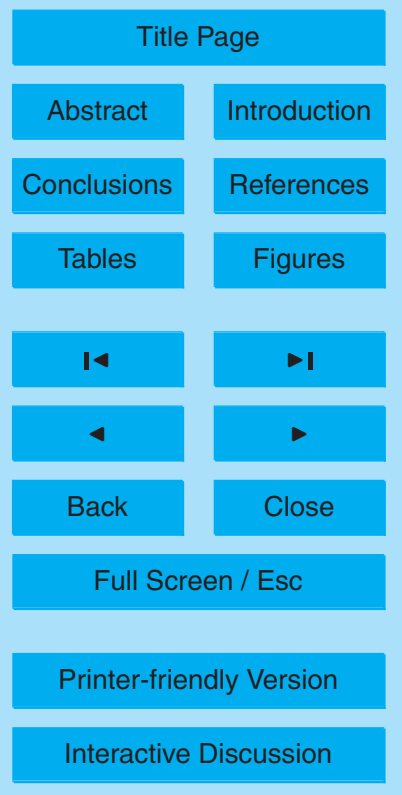


importance of small ice crystals in tropical anvil cirrus, Atmos. Chem. Phys., 9, 5519-5537, 2009, http://www.atmos-chem-phys.net/9/5519/2009/.

King, W. D.: Air flow around PMS canisters, J. Atmos. Ocean. Tech., 3, 197-198, 1986.

Korolev, A. V., Isaac, G. A., Mazin, I. P., and Barker, H. W.: Microphysical properties of con5 tinental clouds from in-situ measurements, Quart. J. Roy. Meteor. Soc., 127, 2117-2151, 2001.

Korolev, A. and Isaac, G. A.: Shattering during sampling by OAPs and HVPS. Part I: Snow particles, J. Atmos. Ocean. Tech., 22, 528-542, 2005.

Lawson, R. P., Baker, B. A., and Schmitt, C. G.: An overview of microphysical properties of Arctic clouds observed in May and July 1998 during FIRE ACE, J. Geophys. Res., 106, 14989-15014, 2001.

McFarquhar, G., Zhang, G., Poellot, M. R., Kok, G. L., McCoy, R., Tooman, T., Fridlind, A., and Heymsfield, A.: Ice properties of single-layer stratocumulus during the Mixed-Phase Arctic Cloud Experiment, J. Geophys. Res., 112, doi:10.1029/2007JD008633, 2007.

Mioche, G., Josset, D., Gayet, J.-F., Pelon, J., Garnier, A., Minikin A., and Schwarzenboeck, A.: Validation of the CALIPSO/CALIOP extinction coefficients from in situ observations in mid-latitude cirrus clouds during CIRCLE-2 experiment. J. Geophys. Res., doi:10.1029/2009JD012376, in press, 2010.

Shcherbakov, V., Gayet, J.-F., Jourdan, O., Minikin, A., Ström, J., and Petzold, A.: Assessment of cirrus cloud optical and microphysical data reliability by applying statistical procedures, J. Atmos. Ocean. Tech., 22, 409-420, 2005.

Strapp, J. W., Albers, F., Reuter, A., Korolev, A. V., Maixner, U., Rashke, E., and Vukovic Z.: Laboratory measurements of the response of a PMS OAP-2DC. J. Atmos. Oceanic Technol., 18, 1150-1170, 2001.

Ström, J., Schumann, U., Gayet, J.-F., et al.: Aerosol and cirrus measurements at midlatitudes on the Southern hemisphere: An overview based on the first INCA experiment, Air Pollut. Rep., 74, Rep. EUR 19,428 EN, European Commission, Brussels, 2001.

Vidaurre, G. and Hallett, J.: Particle Impact and Breakup in Aircraft Measurement, J. Atmos. Ocean. Tech., 26, 972-983, 2009.

so Weber, R. J., Clarke, A. D., Litchy, M., Li, J., Kok, G., Schillawski, R. D., and McMurry, P. $\mathrm{H}$.: Spurious aerosol measurements when sampling from aircraft in the vicinity of clouds, J. Geophys. Res., 103 (D21), 28337-28346, 1998.

\section{Probabilistic model of shattering effect on in-cloud measurements}

V. Shcherbakov et al.

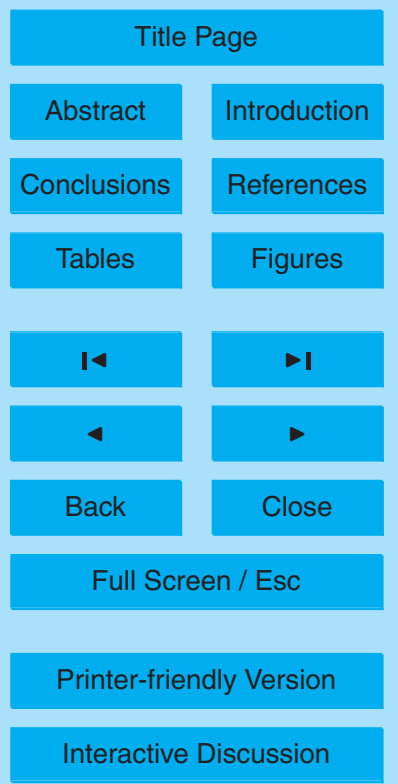

11036 


\section{ACPD}

10, 11009-11046, 2010

\section{Probabilistic model of shattering effect on in-cloud measurements}

V. Shcherbakov et al.

Table 1. Integral parameters of the size distribution D1, D2, and D3.

\begin{tabular}{llll}
\hline & $\mathrm{D} 1$ & $\mathrm{D} 2$ & $\mathrm{D} 3$ \\
\hline$N_{0}\left(\mathrm{~cm}^{-3}\right)$ & 2.6 & 1.8 & 1.4 \\
$E_{0}\left(\mathrm{~km}^{-1}\right)$ & 0.47 & 0.55 & 0.68 \\
$I W C_{0}\left(\mathrm{mg} \mathrm{m}^{-3}\right)$ & 5 & 11 & 18 \\
$d_{\text {effo }}(\mu \mathrm{m})$ & 36 & 68 & 89 \\
\hline
\end{tabular}

Title Page

Abstract Introduction

Conclusions

References

Tables

Figures

14

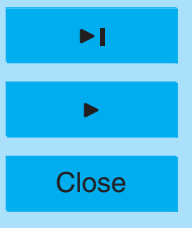

Back

Close

Full Screen / Esc

Printer-friendly Version

Interactive Discussion 


\section{ACPD}

$10,11009-11046,2010$

\section{Probabilistic model of shattering effect on in-cloud measurements}

Table 2. Relative values of integral parameters of the shattered cloud particles for the inlet diameters $10 \mathrm{~mm}$ (Polar Nephelometer) and $40 \mathrm{~mm}$ (FSSP-300).

V. Shcherbakov et al.

\begin{tabular}{|c|c|c|c|}
\hline & D1 & D2 & D3 \\
\hline \multicolumn{4}{|c|}{ Inlet diameter $10 \mathrm{~mm}$} \\
\hline$\delta N(\%)$ & 0.16 & 0.19 & 0.22 \\
\hline$\delta \operatorname{Ext}(\%)$ & 0.71 & 1.34 & 1.77 \\
\hline$\delta I W C(\%)$ & 2.65 & 3.81 & 4.29 \\
\hline \multicolumn{4}{|c|}{ Inlet diameter $40 \mathrm{~mm}$} \\
\hline$\delta N(\%)$ & 0.04 & 0.05 & 0.05 \\
\hline$\delta \operatorname{Ext}(\%)$ & 0.18 & 0.34 & 0.45 \\
\hline$\delta I W C(\%)$ & 0.67 & 0.96 & 1.09 \\
\hline
\end{tabular}

Title Page

Abstract

Conclusions

Tables

Tables

14

4

Back
Introduction

References

Figures

-

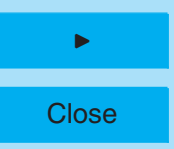

Full Screen / Esc

Printer-friendly Version 


\section{ACPD}

$10,11009-11046,2010$

\section{Probabilistic model of shattering effect on in-cloud measurements}

V. Shcherbakov et al.

Table 3. Effective diameters of the shattered cloud particles for the inlet diameters $10 \mathrm{~mm}$ (Polar Nephelometer) and $40 \mathrm{~mm}$ (FSSP-300).

\begin{tabular}{|c|c|c|c|}
\hline & D1 & D2 & D3 \\
\hline \multicolumn{4}{|c|}{ Inlet diameter $10 \mathrm{mr}$} \\
\hline$(\mu \mathrm{m})$ & 133 & & 217 \\
\hline$d_{\text {eff2 }}(\mu \mathrm{m})$ & 134 & 193 & 218 \\
\hline
\end{tabular}

Title Page

Abstract Introduction

Conclusions References 

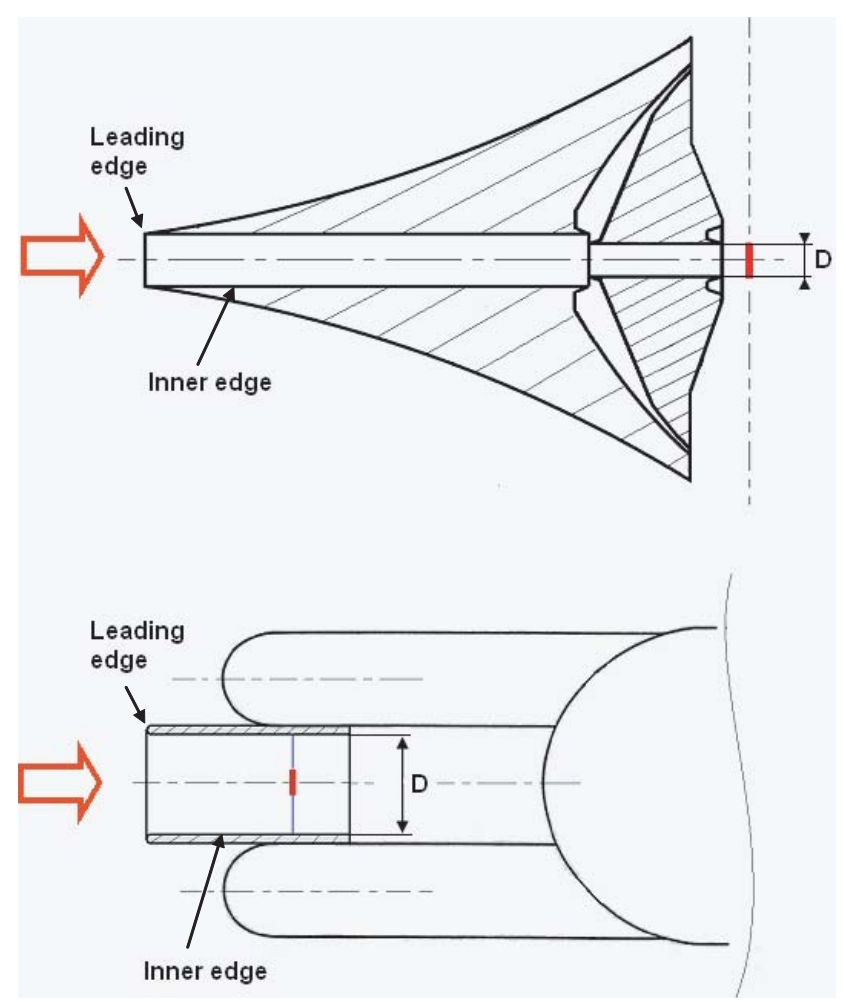

Fig. 1. Sketches of the inlets of the Polar Nephelometer (upper panel) and FSSP probe (bottom panel). Red lines represent the sampling volume. $D$ is the inlet diameter.

\section{ACPD}

10, 11009-11046, 2010

Probabilistic model of shattering effect on in-cloud measurements

V. Shcherbakov et al.

Title Page

Abstract

Introduction

Conclusions

References

Tables

Figures

14

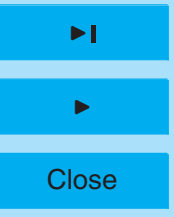

Back

Full Screen / Esc

Printer-friendly Version

Interactive Discussion 


\section{ACPD}

10, 11009-11046, 2010

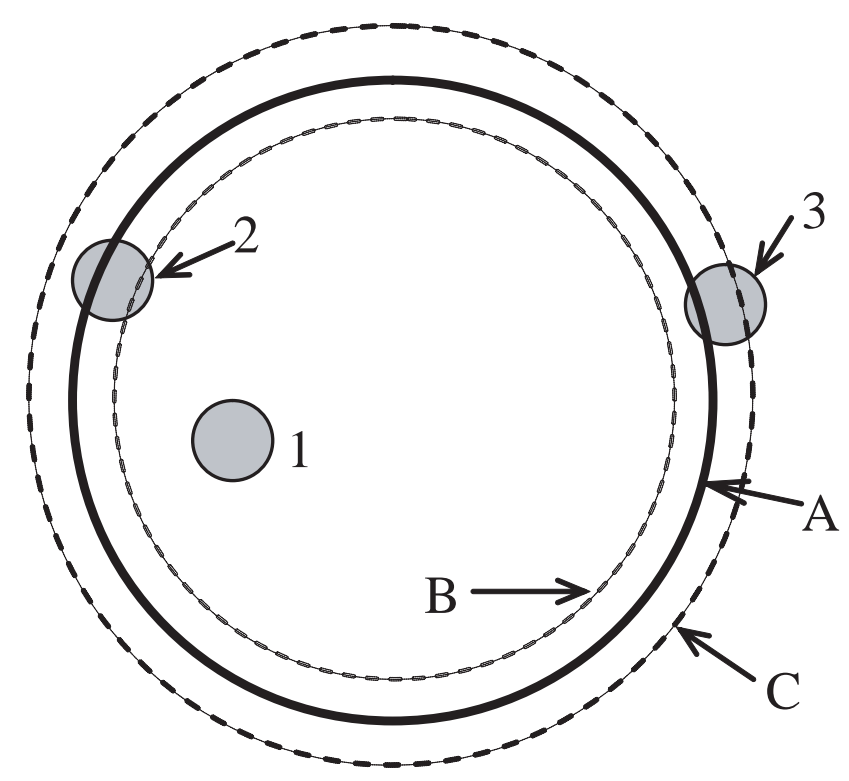

Probabilistic model of shattering effect on in-cloud measurements

V. Shcherbakov et al.

Title Page

Abstract

Introduction

Conclusions

References

Tables

Figures

14

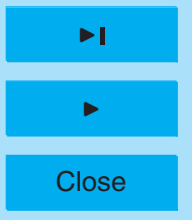

Back

Full Screen / Esc

Printer-friendly Version

Interactive Discussion 


\section{ACPD}

10, 11009-11046, 2010

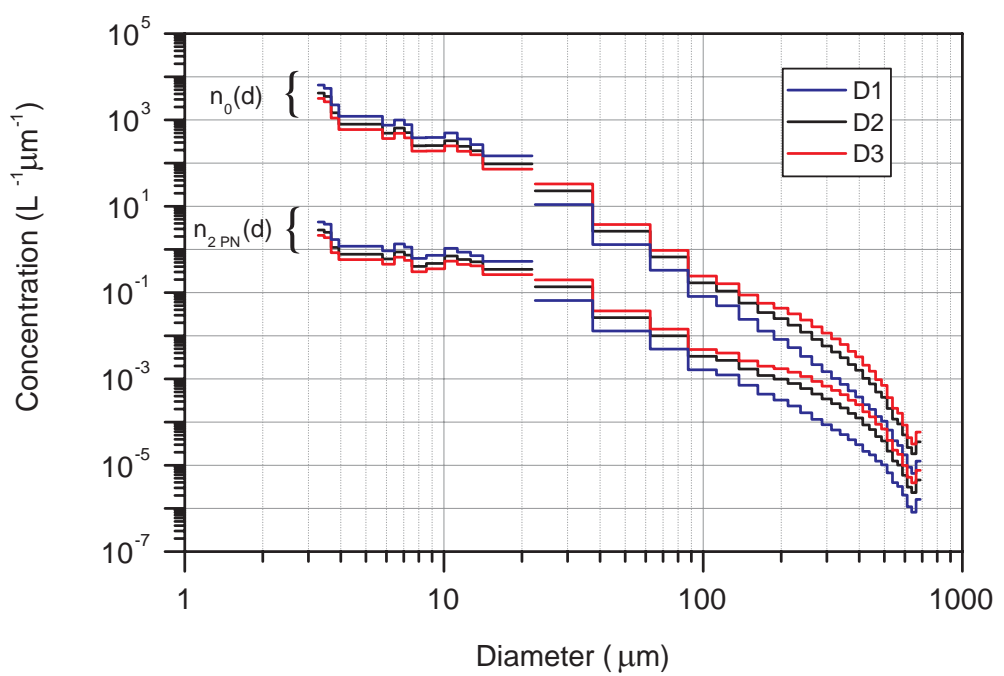

Probabilistic model of shattering effect on in-cloud measurements

V. Shcherbakov et al.

Title Page

Abstract Introduction

Conclusions

References

Tables

Figures

14

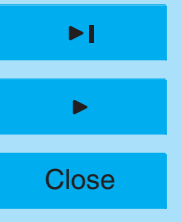

Back

Close

Full Screen / Esc

Printer-friendly Version

Interactive Discussion 


\section{ACPD}

10, 11009-11046, 2010

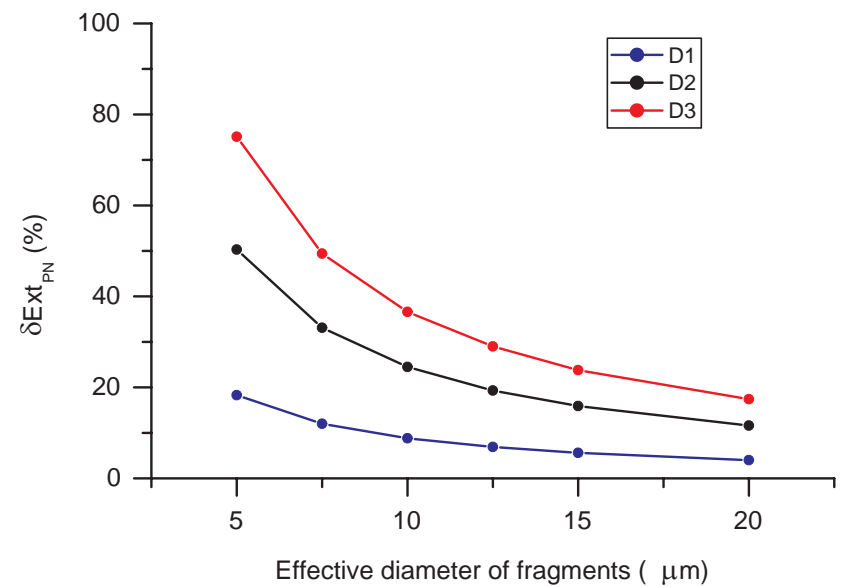

Fig. 4. Overestimation factor due to ice particle shattering on extinction measurements from the Polar Nephelometer as a function of the effective diameter of the fragment particles. D1, D2 and D3 address the size distributions represented in Fig. 3.

\section{Probabilistic model of shattering effect on in-cloud measurements}

V. Shcherbakov et al.

Title Page

Abstract Introduction

Conclusions References

Tables Figures

14

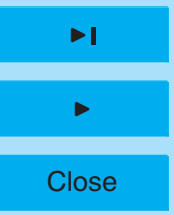

Back

Full Screen / Esc

Printer-friendly Version

Interactive Discussion 


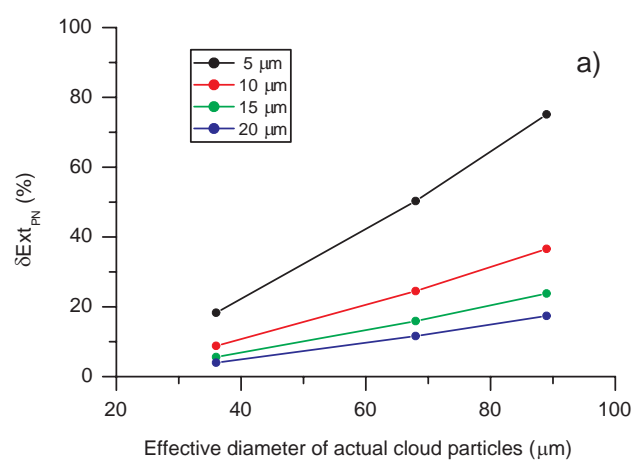

\section{ACPD}

$10,11009-11046,2010$

\section{Probabilistic model of shattering effect on in-cloud measurements}

V. Shcherbakov et al.

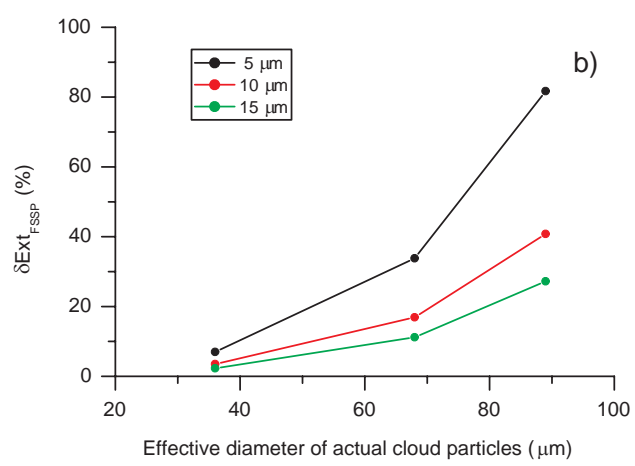

Title Page

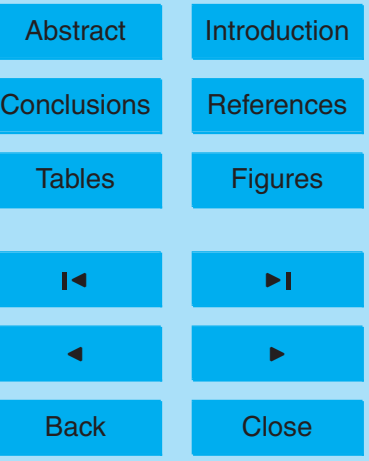

Full Screen / Esc

Fig. 5. Overestimation factors due to ice particle shattering on extinction measurements from Polar Nephelometer (upper panel) and FSSP-300 (bottom panel) as a function of the effective diameter of the actual particle size distributions on Fig. 3. Values of 5, 10, 15 and $20 \mu \mathrm{m}$ address the effective diameters of the fragment particles.

Printer-friendly Version

Interactive Discussion 


\section{ACPD}

10, 11009-11046, 2010
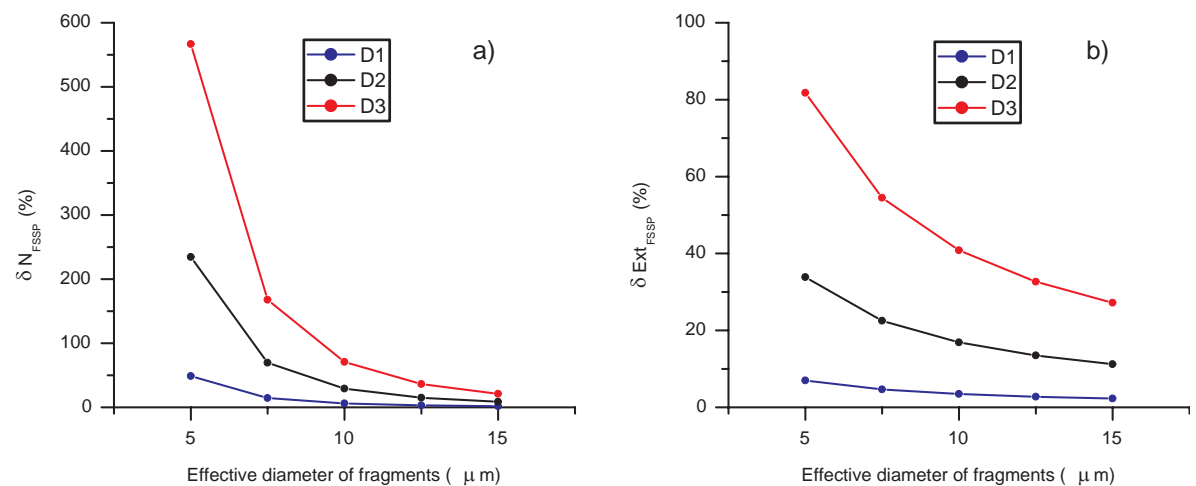

\section{Probabilistic model of shattering effect on in-cloud measurements}

V. Shcherbakov et al.

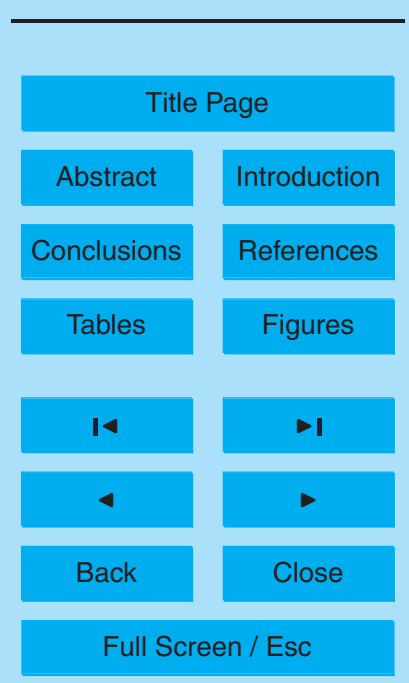

Printer-friendly Version

Fig. 6. Overestimation factors due to ice particle shattering on number particle concentration (left panel) and extinction measurements (right panel) from the FSSP-300 as a function of the effective diameter of the fragment particles. D1, D2 and D3 address the size distributions represented in Fig. 3. 